\title{
MOMENTUM TRADING AND LIMITS TO ARBITRAGE
}

\author{
A Dissertation \\ by \\ WILLIAM JOSEPH ARMSTRONG \\ Submitted to the Office of Graduate Studies of \\ Texas A\&M University \\ in partial fulfillment of the requirements for the degree of \\ DOCTOR OF PHILOSOPHY
}

May 2012

Major Subject: Finance 
MOMENTUM TRADING AND LIMITS TO ARBITRAGE

\author{
A Dissertation \\ by \\ WILLIAM JOSEPH ARMSTRONG
}

\begin{abstract}
Submitted to the Office of Graduate Studies of Texas A\&M University

in partial fulfillment of the requirements for the degree of

DOCTOR OF PHILOSOPHY
\end{abstract}

Approved by:

Chair of Committee, Sorin Sorescu

Committee Members, James Kolari

Ralitsa Petkova

Lynn Rees

Head of Department, Sorin Sorescu

May 2012

Major Subject: Finance 


\begin{abstract}
Momentum Trading and Limits to Arbitrage. (May 2012 )

William Joseph Armstrong, B.S., University of Colorado, Boulder; M.B.A., Texas

A\&M University

Chair of Advisory Committee: Dr. Sorin Sorescu
\end{abstract}

An extensive body of research supports the momentum strategy's persistence but disagrees on the underlying source of its profitability. A key obstacle to distinguishing between behavioral and rational explanations of momentum is that mispricing is unobservable. This dissertation studies the endogenous relationship between momentum trading and mispricing. The basic idea is that momentum trades can impede arbitrage when they are in the opposite direction of arbitrage trades and reinforce arbitrage when they are in the same direction. A simple model suggests that when momentum trades reinforce the arbitrage process, momentum strategy returns contain relatively less mispricing than when momentum trades impede the arbitrage process. Empirical results show that an arbitrage-reinforcing strategy has significantly higher average returns that are largely related to risk and do not reverse in subsequent periods, while an arbitrage-impeding strategy exhibits significant longterm reversal consistent with more mispricing. Additional tests show that winners have higher future growth rates than losers consistent with cross-sectional differences in expected returns. Overall, the evidence suggests that momentum profitability is largely related to risk which is partially masked by mispricing. An important implication of this model is that, like noise traders, trading strategies that do not condition on relative value can impede arbitrage. 


\section{ACKNOWLEDGMENTS}

I would like to start by thanking my dissertation chair, Sorin Sorescu, who challenged me to develop a deeper insight into my work throughout the dissertation process. I am also grateful for the encouragement and support of my dissertation committee James Kolari, Ralitsa Petkova, and Lynn Rees. I have also benefited greatly from the comments and suggestions of faculty members outside of my dissertation committee, including Shane Johnson and Hagen Kim. I am also thankful for the friendship and support of my fellow PhD students, Kyle Tippens, Ferhat Akbas, Egemen Genc, and Hursit Celil. I would like to thank Texas A\&M University, Mays Business School, and the Finance Department for financial support.

Finally and most importantly, I thank my wife, Anne Armstrong, and our children, Nathan, Jake and Sarah, for their patience, support, and love throughout this process. 
TABLE OF CONTENTS

Page

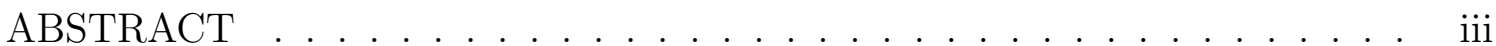

ACKNOWLEDGMENTS .............................. iv

TABLE OF CONTENTS . . . . . . . . . . . . . . . . . v

LIST OF TABLES ................................... vii

LIST OF FIGURES ....................... . . viii

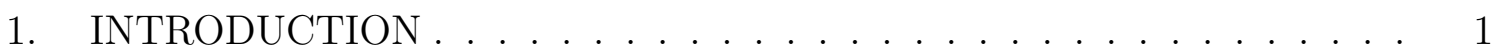

2. MOMENTUM TRADING AND ARBITRAGE . . . . . . . . . . . . 7

2.1 Momentum . . . . . . . . . . . . . . . . . . . 7

2.2 Limits to Arbitrage . . . . . . . . . . . . . . . . . . . . . 8

2.3 Empirical Methods . . . . . . . . . . . . . . . . . . . . 10

3. MOMENTUM, ARBITRAGE, AND FUTURE STOCK RETURNS . . . 15

3.1 Data and Descriptive Statistics . . . . . . . . . . . . . . 16

3.2 Portfolio Results . . . . . . . . . . . . . . . . . . . . . 21

3.3 Regression Results . . . . . . . . . . . . . . . . . 27

4. CONDITIONAL MOMENTUM STRATEGIES . . . . . . . . . . . . 32

4.1 Methodology . . . . . . . . . . . . . . . . . . . 32

4.2 Conditional Momentum Strategy Performance . . . . . . . . . . . . . 35

4.3 Long-term Reversal . . . . . . . . . . . . . . . . . . . . . . . 36

4.4 Expected Momentum Profits . . . . . . . . . . . . . . . . . . . 41

4.5 Expected Growth Rates . . . . . . . . . . . . . . . . . . 45

4.6 Short-Sale Constraints and Overvaluation . . . . . . . . . . . . 50

5. MOMENTUM, MiSPRICING, AND THE VALUE STRATEGY . . . . . 54

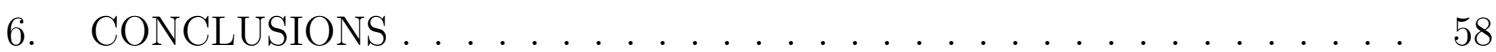

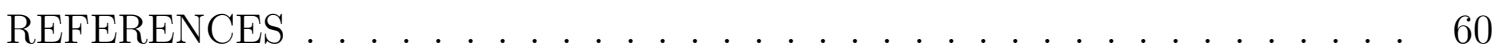

APPENDIX A. A MODEL OF MOMENTUM TRADING AND ARBITRAGE 66 


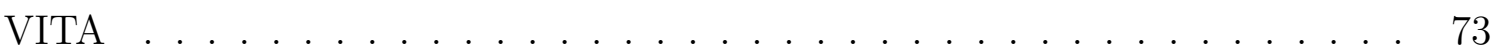




\section{LIST OF TABLES}

TABLE

Page

3.1 Descriptive Statistics $(1967-2010) \ldots \ldots \ldots \ldots$

3.2 Relative Misvaluation Portfolio Returns (1967-2010) . . . . . . . . . . . 22

3.3 Momentum and Relative Misvaluation Portfolios (1967-2010) . . . . . . 24

3.4 Fama-MacBeth Regressions using Individual Stocks (1967-2010) . . . . . 29

4.1 Conditional Momentum Strategy Summary Statistics (1967-2010) . . . . 34

4.2 Conditional Momentum Strategy Performance (1969-2010) . . . . . . . . 37

4.3 Conditional Momentum Strategy Average Annual Post-Formation Re-

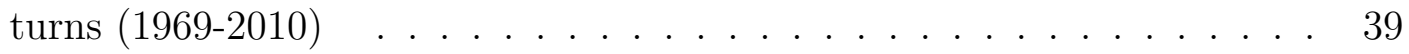

4.4 Expected Momentum Profits (1967-2010) . . . . . . . . . . . 43

4.5 Conditional Momentum Strategies and Firm Operating Performance (1967-

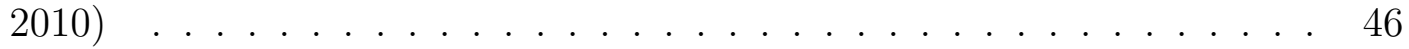

4.6 Misvaluation and Stock Characteristics (1967-2010) . . . . . . . . . 52

5.1 Conditional Momentum Strategies and the Value Strategy (1967-2010) 55 


\section{LIST OF FIGURES}

FIGURE

Page

3.1 Residual Firm Value (Jan. 1967 to Dec. 2010) . . . . . . . . . . . . . . . 20

3.2 Residual Firm Value of Winners and Losers (Jan. 1967 to Dec. 2010) . . 26 


\section{INTRODUCTION}

Jegadeesh and Titman (1993) show that a momentum strategy formed with a long position in recent winners and a short position in recent losers generates positive and significant returns for up to 12 months following portfolio formation. They also show that returns to the underlying stocks exhibit significant return reversal in the second and third years following portfolio formation. The ensuing literature generally suggests that momentum strategy returns are robust to risk-adjustment, persist in out-of-sample tests, and exist in international markets.

While the empirical literature strongly supports the persistence of the momentum strategy, there is significant disagreement as to the underlying source(s) of its profitability. Behavioral explanations suggest that momentum is the result of mispricing caused by behavioral biases of market participants, while rational explanations suggest that momentum is the result of cross-sectional differences in expected returns due to time-varying or omitted risk factors. In spite of the significant differences in the underlying source(s) of momentum profitability, behavioral and rational models generate similar predictions because they are designed to explain the return pattern observed in the data (e.g. short-term continuation and long-term reversal).

In this paper I use the endogenous relationship between momentum trading and security mispricing to analyze rational and behavioral explanations of momentum. A key obstacle to separating behavioral and rational explanations is that mispricing is unobservable. Behavioral models suggest that momentum profits are the result of mispricing which is generated when investors trade in a biased manner. Mispricing can be due to either investor overreaction where investors push prices away from fundamental value, or investor underreaction where new information is not fully incorporated into prices. In an efficient market, mispricing should be fleeting

This dissertation follows the style of Journal of Finance. 
as arbitrageurs quickly eliminate any mispricing (e.g. Fama (1965)). If momentum profits are the result of mispricing, there should be some market friction that enables mispricing to persist.

Theoretical work in the limits to arbitrage literature suggests that arbitrage is risky and that under certain conditions mispricing may persist, and perhaps deepen. DeLong, Shleifer, Summers, and Waldmann (1990) show that arbitrageurs will reduce their investment in a mispriced security if there is a risk that noise traders will cause mispricing to deepen resulting in a short-term loss on the arbitrageur's position. The ensuing literature suggests that arbitrage intensity will be reduced when arbitrageurs are risk-averse, invest using other peoples' money, or incur holding costs.

The basic idea of this dissertation is that arbitrageurs may reduce arbitrage intensity when momentum trades are expected to push prices away from fundamental value. Similarly, arbitrageurs may increase arbitrage intensity when they expect momentum trades to reinforce the arbitrage process and help correct mispricing faster. Stocks in the former case should contain relatively more mispricing, while stocks in the latter case should contain relatively less mispricing. In Appendix A I develop a simple model that demonstrates the effect of momentum trades on arbitrage intensity and mispricing. The model suggests that stocks should contain relatively more mispricing when momentum trades are in the opposite direction of arbitrage trades and relatively less mispricing when trades are aligned.

To empirically test behavioral and rational explanations of momentum, I combine the direction of momentum trades with a proxy for the direction of arbitrage trades. Since mispricing is unobservable, I use a measure of relative misvaluation as a proxy for the direction of arbitrage trades. ${ }^{1}$ Measures of relative misvaluation proxy for the information set of the average arbitrageur as they capture deviations in a firm's equity valuation relative to peer firm valuations. If the measure reasonably captures

\footnotetext{
${ }^{1}$ For the purpose of this paper it is not critical that the measure of relative misvaluation distinguishes between mispricing and unobserved differences in expected returns. The arbitrageur does not directly observe mispricing and thus must make investments based on relative differences in valuation after controlling for observable differences in discount rates and expected cashflows.
} 
the direction of arbitrage trades then an arbitrageur should profit by buying (selling) stocks that appear to be undervalued (overvalued) relative to its peers.

In this paper the primary measure of relative misvaluation is estimated using the valuation framework developed in Rhodes-Kropf, Robinson, and Viswanathan (2005) which measures the value of a firm relative to its industry peers after controlling for differences in observable accounting information. ${ }^{2}$ Detailed portfolio and regression analyses demonstrate that relatively undervalued stocks have significantly higher returns than relatively overvalued stocks. These results are robust to risk-adjustment, stronger in recent winners, and stronger in the period following the publication of Jegadeesh and Titman (1993). Overall, these findings support using this measure as a proxy for the direction of arbitrage trades.

Using the predictions of the model and the direction of arbitrage trades, I construct two conditional momentum strategies: one using stocks where momentum trades are likely to impede arbitrage and one using stocks where trades are likely to reinforce arbitrage. If arbitrageurs adjust their capital intensity according to the expected level of momentum trades, stocks where momentum trades impede arbitrage should contain relatively more mispricing than stocks where trades reinforce arbitrage. If momentum profitability is the result of mispricing, the strategy where momentum trades impede arbitrage should have relatively higher average returns. Contrary to this prediction, I find that the strategy where momentum trades reinforce arbitrage, and is expected to contain relatively less mispricing, has significantly higher returns that are more than double the returns to the strategy where momentum trades impede arbitrage. I show that this difference in returns is robust to risk adjustment and persistent across sub-periods.

The return reversal of momentum stocks over the two to five years following portfolio formation is frequently cited as evidence of investor overreaction. While rational

${ }^{2}$ This approach is analogous to an integrated desktop analysis performed by a financial analyst who values firms relative to their peers using a combination of measures such as $M / B, P / E, R O E$, and leveraged cost of capital. As discussed in Section 2, the main results are robust to using alternative proxies for the direction of arbitrage trades. 
models can replicate the short-term continuation observed in momentum strategies, they have difficulty generating the magnitude of long-term reversal observed in the data. If momentum profitability is due to investor overreaction (e.g. Daniel, Hirshleifer, and Subrahmanyam (1998)), long-term reversal should be stronger in the strategy where momentum trades are in the opposite direction of arbitrage trades. Consistent with this prediction, I find significant long-term reversal for up to five years following portfolio formation when momentum trades impede the arbitrage process, but no evidence of long-term reversal at any horizon when momentum trades reinforce the arbitrage process. This evidence is consistent with a higher level of mispricing when momentum trades are in the opposite direction of arbitrage trades.

The long-term reversal tests combined with the average returns of the conditional strategies cast doubt on the ability of mispricing to explain average momentum profitability. The subset of momentum stocks that appear to contain relatively more mispricing also have significantly lower returns.

One could argue that the results so far only rule out mispricing from the perspective of investor overreaction, but not investor underreaction. Behavioral models of Barberis, Shleifer, and Vishny (1998) and Hong and Stein (1999) suggest that momentum profitability may result from a combination of investor overreaction and investor underreaction. If momentum profitability is the result of investor underreaction, this suggests that all market participants, including arbitrageurs, systematically underreact to observable, value-relevant information. However, the model in Appendix A suggests that arbitrageurs will increase their capital intensity when momentum trades are expected to reinforce the arbitrage process (relative to the case of no momentum trades). Thus, there should be little mispricing in momentum stocks when arbitrageurs are able to observe past returns and infer that momentum trades will aid in the correction of mispricing. If arbitrageurs supply sufficient capital to eliminate mispricing due to investor underreaction, then momentum profits should be largely due to cross-sectional differences in expected returns. 
To study the relationship between momentum profitability and cross-sectional differences in expected returns I estimate the proportion of momentum strategy returns that can be explained as compensation for risk exposure. The long-term reversal findings suggest that at least a subset of momentum stocks are mispriced and thus their returns may contain a mispricing component. The noise that mispricing injects into the return series may confound empirical tests of risk exposure. If momentum profitability is due to rational explanations rather than investor underreaction, momentum returns should have higher exposure to priced risk factors when the return series contains less mispricing. Empirical results show that a significantly larger proportion of momentum returns to the arbitrage-reinforcing strategy are explained as compensation for risk. These results are robust across risk-models including the Fama and French (1993) three-factor model and the Chen, Roll, and Ross (1986) macroeconomic risk factors. Using the Chen, Roll, and Ross (1986) factors I find that more than two-thirds of the realized momentum returns are explained as risk compensation. These findings suggest that average momentum profitability is largely explained by risk exposure rather than investor underreaction.

I also find that while the strategy where momentum trades impede arbitrage loads significantly on priced risk factors such as the change in industrial production, the significant level of mispricing masks the level of risk compensation and appears to reduce the average returns in this strategy. Further tests provide evidence that future sales and asset growth rates are increasing (decreasing) in the winners (losers) groups of both strategies, yet there is significant reversion in the numerator of the price-earning multiples for stocks where momentum trades impede arbitrage. These findings are consistent with rational explanations of momentum profitability where risk exposure is masked by a significant level of mispricing which appears to reduce rather than explain momentum profitability.

I also find that returns to the momentum and value strategies interact in an interesting manner. When the arbitrage-impeding momentum strategy is profitable, the 
value strategy earns zero returns. However, when momentum traders are unsuccessful in pushing prices away from fundamental value, relative value traders earn profits of almost one-percent per month. This finding provides further evidence consistent with momentum trades impeding the arbitrage process.

While the existing literature supports the presence of mispricing (e.g. Jegadeesh and Titman (2001)), this is the first paper (to my knowledge) that isolates the influence of mispricing on momentum profitability by conditioning empirical tests on the expected level of mispricing. The evidence suggests that momentum profitability is largely related to cross-sectional differences in expected returns. Long-term reversal, the strongest evidence supporting the presence of mispricing, is only present in the least profitable conditional strategy and thus it appears unlikely that behavioral explanations are the primary source of momentum profitability. The significant proportion of momentum profits explained as compensation for risk mitigates claims that momentum profits may be the result of investor underreaction. Further, the mispricing component of momentum returns appears to mask the underlying crosssectional differences in expected returns between winners and losers.

Overall, it appears that the interaction of momentum traders and arbitrageurs has implications for market efficiency. Momentum or relative strength traders appear to impede arbitrage for relatively overvalued past winners and undervalued past losers. The results suggest that, like noise traders, trading strategies that do not condition on relative value can impose constraints on arbitrage activity.

The rest of the dissertation is organized as follows. Section 2 develops the motivation and empirical approach. Section 3 documents the relationship between momentum, misvaluation, and future returns. Section 4 documents the main results. Section 5 discusses the interaction of the momentum strategy, value strategy, and mispricing and Section 6 concludes. Appendix A provides a simple model of the the interaction of momentum traders and arbitrageurs. 


\section{MOMENTUM TRADING AND ARBITRAGE}

\subsection{Momentum}

Jegadeesh and Titman (1993) show that a momentum strategy formed with a long position in recent winners and short position in recent losers generates significant and positive returns for up to 12 months following portfolio formation. They also show that returns to the underlying stocks exhibit reversal in the second and third years following portfolio formation. An important aspect of the momentum strategy is that portfolio formation is unconditional with respect to the fundamental value of the underlying stocks. The empirical literature strongly supports the persistence of the momentum strategy but does not agree on the underlying source(s) of its profitability. ${ }^{1}$

Behavioral explanations generally model momentum as a temporary divergence of market prices from fundamental values due to behavioral biases of market participants (e.g. Barberis, Shleifer, and Vishny (1998), Daniel, Hirshleifer, and Subrahmanyam (1998), and Hong and Stein (1999)). Rational explanations generally model momentum as a divergence of market prices from predicted fundamental value that is the result of time-variation in expected returns or omitted risk factors (e.g. Johnson (2002) and Sagi and Seasholes (2007)). In spite of the significant differences in the underlying source(s) of momentum profitability, behavioral and rational models generate similar predictions because they are designed to explain the return pattern observed in the data (i.e. short-term continuation and long-term reversal).

If behavioral explanations are correct then momentum is the result of investor biases that cause market prices to deviate from fundamental value. The literature suggests that momentum returns could be the due to either investor underreaction

${ }^{1}$ See, for example, Fama and French (1996), Conrad and Kaul (1998), Rouwenhorst (1998), Moskowitz and Grinblatt (1999), Grundy and Martin (2001), Jegadeesh and Titman (2001), Chordia and Shivakumar (2002), Lewellen (2002), Griffin, Ji, and Martin (2003), Cooper, Gutierrez, and Hameed (2004), Fama and French (2008), Gutierrez and Kelley (2008), Liu and Zhang (2008), and Novy-Marx (2011). 
or overreaction to value-relevant information. For example, Daniel, Hirshleifer, and Subrahmanyam (1998) model momentum as the result of investor overreaction where the investor is overconfident about the precision of his private information and is biased in the way he reacts to new public information. Hong and Stein (1999) generate momentum using two types of traders, news watchers and momentum traders. The biases of the news watchers cause them to underreact to the trading of other news watchers. Thus information is slowly incorporated into prices leading to return predictability. The model's result is that momentum is initially generated by the underreaction of the news watchers. Since momentum traders only condition on past returns they start trading as news watchers incorporate information, but continue trading after the news is fully incorporated leading them to push prices beyond the fundamental value observed by the news watchers in aggregate. Both models generate the return pattern observed in the data: short-term return continuation which generates momentum profits, and long-term reversal of the portion of returns that are due to investor overreaction.

A key obstacle to distinguishing between behavioral and rational explanations is that mispricing is unobservable. The existence of a persistent and profitable trading strategy that is the result of mispricing contradicts the very notion of market efficiency. If momentum profits are the result of mispricing, there should be some market friction that prevents the mispricing from being corrected. One approach to ascertain when momentum stocks are likely to contain more mispricing is to identify sources of risk for arbitrageurs which may lead to a reduction in arbitrage intensity. A reduction in arbitrage intensity, all else equal, should result in relatively more mispricing.

\subsection{Limits to Arbitrage}

In an efficient markets framework, arbitrageurs ensure that prices fully reflect all available information and thus mispricing is transient (e.g. Fama (1965)). Shleifer 
and Vishny (1997) develop a model where an arbitrageur may reduce his investment if there is a positive probability of a performance shock that may require him to raise more capital (or unwind his positions) before correction of the mispricing. This reduction in arbitrage capital prevents the mispricing from being completely eliminated. Similarly, arbitrageurs may anticipate noise traders pushing prices away from fundamental value and reduce their investment in the arbitrage opportunity (i.e. DeLong, Shleifer, Summers, and Waldmann (1990), and Shleifer and Summers (1990)). It seems reasonable that, like noise traders, momentum traders can impede arbitrage if their trades increase the risk of a performance shock to arbitrageurs. This paper considers momentum traders as a special case of noise traders in that the volume and intensity of trading can be inferred by observing past returns.

In Appendix A I develop a simple model of the interaction of momentum traders and arbitrageurs to examine the influence of mispricing on the profitability of the momentum strategy. The intuition is straightforward; momentum trades aligned with arbitrage trades facilitate price convergence to fundamental value, while momentum trades in the opposite direction of arbitrage trades slow price convergence and may push prices further away from fundamental value.

If arbitrageurs anticipate momentum trades impeding price convergence, they may reduce the level of capital committed towards the arbitrage opportunity. De Long, Shleifer, Summers and Waldmann (1990) show that arbitrageurs face the risk that noise traders may push prices away from fundamental value leading arbitrageurs to trade less aggressively. Kondor (2009) develops a model where a positive probability of mispricing deepening can lead arbitrageurs to reduce their arbitrage intensity. Thus unconditional momentum trading can lead to a reduction in arbitrage intensity which allows mispricing to persist (or deepen).

Similarly, arbitrageurs may increase arbitrage intensity when they expect that momentum trades will reinforce the arbitrage process. Abreu and Brunnermeier (2002) show that when arbitrageurs become informed sequentially and incur holding 
costs, they will delay arbitrage and try to "time the market." They argue that the uncertainty around when other arbitrageurs will act on an opportunity leads to a "synchronization risk". The model in Appendix A suggests that visibility of past returns can act as a coordination mechanism that reduces the synchronization risk which, all else equal, enables arbitrageurs to act sooner when momentum traders reinforce the arbitrage process and later when momentum trades impede the arbitrage process.

\subsection{Empirical Methods}

The model suggests that momentum stocks should contain relatively more mispricing when momentum trades are in the opposite direction of arbitrage trades, while stocks where trades are in the same direction as arbitrage trades will contain relatively less mispricing. While the direction and intensity of momentum trades can easily be inferred from past returns, the direction of arbitrage trades must be inferred from proxies of relative misvaluation. To be an effective proxy for the direction of arbitrage trades, the measure should be based on observable, value-relevant information and capture differences in valuation between a firm and its peers. As arbitrageurs trade to generate profits, the measure should also predict returns in the cross-section of stocks. That is, undervalued stocks should have relatively higher returns than overvalued stocks.

Over the last three decades, researchers have identified a wide range of measures which appear to predict returns in the cross-section of stocks. ${ }^{2}$ Whether the result of behavioral or rational processes, cross-sectional return predictability generally implies that relatively undervalued stocks have higher average returns than relatively overvalued stocks. Expected returns to misvalued securities include the expected re-

${ }^{2}$ See, for example, Basu (1977), Banz (1981), De Bondt and Thaler (1985), Jegadeesh (1990), Lehmann (1990), Fama and French (1992), Jegadeesh and Titman (1993), Sloan (1996), Amihud (2002), Ang, Hodrick, Xing, and Zhang (2006), Daniel and Titman (2006), and Cooper, Gulen, and Schill (2008). 
turn based on observed risk factors as well as the expected correction of the apparent misvaluation. The misvaluation component, the source of cross-sectional predictability, represents expected arbitrage profits in the case of true security mispricing or unmodeled risk premia in the case of omitted risk factors or time-varying risk premia. ${ }^{3}$

A frequently used proxy for relative value is the market-to-book equity ratio $(M / B)$ or its inverse, the book-to-market equity ratio $(B / M)$. The $M / B$ ratio intuitively reflects the average market price for one dollar of the firm's book equity. A related measure, the industry-adjusted $M / B$ equity ratio $(M B E-I A)$, captures the deviation in the market price for one dollar of book equity from the industry-average price of book equity. Industry-adjustment captures the average price of intangibles within an industry which may differ from the market wide price of intangibles. Industry adjustment ensures that the measure is not simply a sort on industry. For example, sorting stocks according to their $M / B$ ratio is correlated with sorting on industry as firms in industries such as technology will have relatively high $M / B$ ratios on average, while firms in industries like utilities will have relatively low $M / B$ ratios on average. Measures of relative misvaluation, such as the industry-adjusted $M / B$, capture deviations in firm valuations from the average valuations of their industry peers. Thus, relatively overvalued utilities and technology firms alike have high $M B E-I A$ measures, while relatively undervalued utilities and technology firms have low $M B E-I A$ measures. ${ }^{4}$

In this dissertation, the primary measure for the direction of arbitrage trades is residual firm value $(R F V)$ estimated using the market-to-book equity decomposi-

\footnotetext{
${ }^{3}$ In this dissertation, mispricing represents the difference between market price and unobserved fundamental value, while relative misvaluation represents the difference between market price and predicted fundamental value. Relative misvaluation thus reflects either mispricing or cross-sectional differences in expected returns due to time-varying or omitted risk factors.

${ }^{4} \mathrm{An}$ alternative measure of relative misvaluation is industry-adjusted market-to-book value of assets (MBA-IA) which represents the difference between the market price of a dollar of firm assets from the industry average. Other measures, with similar interpretations, include the industry-adjusted price-to-earnings and price-to-sales ratios.
} 
tion developed in Rhodes-Kropf, Robinson, and Viswanathan (2005, RKRV). ${ }^{5}$ I use RKRV's regression-based methodology as it provides the flexibility to control for cross-sectional differences in book equity, net income, and leverage (cost of equity) at the same time. ${ }^{6}$ RKRV's approach decomposes market value into predicted and residual value components where the residual value is net of industry-average intangible values. This approach allows regression slopes to vary across industries and across time. ${ }^{7}$

Residual firm value is computed as the difference between a security's market price and its predicted intrinsic value where unobserved intrinsic value is estimated using publicly available accounting information. Following RKRV's approach, I estimate $R F V$ using within-industry, cross-sectional valuation regressions where industry is defined using the Fama and French 12 industry classification. The coefficient estimates are used to compute predicted intrinsic value and residual firm value. While RKRV use annual regressions, I am interested in linking this measure, as a proxy for the direction of arbitrage trades, with monthly momentum trades. Changes in $R F V$ across time capture not only changes in a firm's market value in terms of its observable accounting information, but more importantly, it captures the changing dynamics of the industry through changes in coefficient estimates. Thus firm predicted values change monthly due to changes in industry composition (firms enter and exit), changes in accounting variables, and changes in factor loadings on the accounting variables. The latter component captures the changes in the firm's market value relative to changes in valuation for the rest of the industry. This is arguably

\footnotetext{
${ }^{5}$ The results in this paper are not reliant upon a specific measure of relative misvaluation but are robust to using alternative industry-adjusted measures such as $M / B, M V A / B V A$, or $P / E$.

${ }^{6} \mathrm{An}$ important aspect of relative misvaluation is that omitted risk factors or time-varying risk premia are not directly observable. $R F V$ is based on industry-relative valuation and and as such should reasonably reflect the relative within-industry ranking of misvaluation attributed to the stock by arbitrageurs and relative value traders.

${ }^{7}$ Johnson, Moorman, and Sorescu (2009) demonstrate the importance of considering the industry component in the cross-section of stock returns.
} 
the most important component, as the measure is used as a proxy for the valuation of a firm relative to its peers.

Empirically, RKRV's general approach is to decompose each stock's log marketto-book ratio into an unobserved intrinsic value-to-book ratio plus a pricing error as follows:

$$
m-b=(m-i v)+(i v-b)
$$

where $m$ is the $\log$ market value, $b$ is the $\log$ book value, and $i v$ is the log intrinsic value. Thus the market-to-book ratio is decomposed into pricing error $(m-i v)$ and intrinsic value-to-book $(i v-b)$ ratio.

Intrinsic value is unobservable so it is estimated using monthly within-industry valuation regressions. ${ }^{8}$ Residual firm value $(R F V)$ is computed as the difference between the natural log of market value and predicted intrinsic value. As mentioned earlier, the regression framework allows the estimated slopes to vary across industries and across time. The valuation model is specified as:

$$
m e_{i t}=\alpha_{0 j t}+\alpha_{1 j t} b e_{i t}+\alpha_{2 j t} n i_{i t}^{+}+\alpha_{3 j t} I_{(N I<0)} n i_{i t}^{+}+\alpha_{4 j t} L E V_{i t}+\epsilon_{i t}
$$

where $m e_{i t}$ is $\log$ market equity, $b e_{i t}$ is $\log$ book equity, $n i_{i t}^{+}$is $\log$ absolute value of net income, and $L E V_{i t}$ is book leverage. The net income component is estimated in two parts to separate the effects of firms with negative net income. The second term interacts $n i_{i t}^{+}$with an indicator variable that is equal to one if net income is negative

${ }^{8} \mathrm{RKRV}$ motivate their valuation model as a decomposition of firm market value into book value plus residual income where residual income is defined as the difference between the $R O E_{t}$ and the firm's cost of capital $r_{t}$ :

$$
M_{t}=B_{t}+E_{t} \sum_{\tau=t+1}^{\infty} \frac{\left(R O E_{\tau}-r_{\tau}\right) B_{\tau-1}}{\left(1+r_{\tau}\right)^{\tau}}
$$

RKRV justify regressing log market value on log book value with two identifying restrictions: a) future return on equity is a constant multiple of expected future discount rates and b) book equity is expected to grow at a constant rate. The inclusion of net income is justified by assuming that book value and net income are growing at constant rates. Leverage is included in the model to allow the cost of capital to vary across firms with book leverage different from the industry average. 
and zero otherwise. $R F V$ is computed as the difference between log market equity and predicted intrinsic value (i.e. estimated residual):

$$
R F V=m e_{i t}-\hat{\alpha}_{0 j t}-\hat{\alpha}_{1 j t} b e_{i t}-\hat{\alpha}_{2 j t} n i_{i t}^{+}-\hat{\alpha}_{3 j t} I_{(<0)} n i_{i t}^{+}-\hat{\alpha}_{4 j t} L E V_{i t}
$$

$R F V$ is mean zero monthly within each industry since it is estimated using monthly, within industry, cross-sectional regressions. As implemented, this approach captures deviation in firm values from industry average valuations. $R F V$ is positive when firms are overvalued relative to their industry peers, and negative when firms are undervalued relative to their peers. 


\section{MOMENTUM, ARBITRAGE, AND FUTURE STOCK RETURNS}

In this section I provide analyses that support using residual firm value $(R F V)$ as a proxy for the direction of trade of the average arbitrageur. Mispricing is unobservable and thus arbitrageurs must rely on measures of relative misvaluation estimated using observable information as proxies for mispricing. As noted earlier, the difference between a firm's valuation and the valuations of its peer firms can be due to either mispricing or omitted risk factors. By basing trades on measures of relative misvaluation such as $R F V$, arbitrage or relative value trading will help to correct mispricing in the subset of stocks where this deviation is due to mispricing. Further, arbitrageurs profit on average from the correction of mispricing and/or from earned risk premia making the distinction between mispricing and risk less important. For example, the expected return to a fairly priced stock $i$ can be represented as follows:

$$
E\left[r_{i}-r f\right]=E\left[\beta_{i} \lambda+\epsilon_{i}\right]=E\left[\beta_{i} \lambda\right]
$$

where $r f$ is the risk-free rate, $\beta$ is a vector of stock $i$ 's risk exposure to benchmark risk factors, $\lambda$ is a vector of risk premia, and $\epsilon$ is random noise. Under the assumption that the market price equals fundamental value and the benchmark risk factors are the appropriate set of risk factors, the expected return to the investor is compensation for exposure to the benchmark risk factors.

However, when stocks are relatively misvalued, arbitrageurs or relative value traders earn an $\alpha$ due to the correction of mispricing and/or the exposure to omitted risk factors. ${ }^{1}$ To see this, note that the expected return to relatively misvalued stock $i$ can be written as:

$$
E\left[r_{i}-r f\right]=E\left[\beta_{i} \lambda+M_{i}+\beta_{i}^{\prime} \lambda^{\prime}\right]=E\left[\beta_{i} \lambda+\alpha_{i}\right]
$$

${ }^{1}$ For simplicity in this example, I assume that there is no estimation error in the benchmark factors (e.g. $(\beta \lambda-\hat{\beta} \hat{\lambda})=0)$. 
where $\beta^{\prime}$ is a vector of omitted risk factors, $\lambda^{\prime}$ is a vector of the corresponding risk premia, and $M_{i}$ is the return due to the change in the level of mispricing. $M_{i}$ will be positive (negative) on average when there is a reduction (increase) in the level of mispricing. Because mispricing and omitted risk factors are unobservable, the observed $\alpha$ captures the benchmark risk-adjusted return to the arbitrageur as shown in Equation 3.2.

Even though mispricing is unobservable, arbitrageurs earn a benchmark adjusted profit (on average) from the earned risk premia and/or the correction in mispricing when stocks are misvalued relative to their peers. Thus it seems reasonable that the trades of arbitrageurs are correlated with a trading strategy based on $R F V$ which generates a positive return to buying relatively undervalued stocks and selling relatively overvalued stocks. It is this relative value trading that can be disrupted when a subset of traders, such as momentum traders, do not condition on relative value and thus may push prices away from fundamental value. Detailed portfolio and regression analyses in this section show that RFV predicts returns in the crosssection of stocks. These results are robust to risk adjustment and persistent across sub-periods. As such, RFV appears to be a reasonable proxy for the direction of trade for the average arbitrageur.

\subsection{Data and Descriptive Statistics}

Monthly stock data including price, return, trading volume, and shares outstanding are obtained from the Center for Research in Security Prices ("CRSP") database for all common stocks listed on the NYSE, AMEX and NASDAQ stock exchanges between 1963 and 2010. Annual accounting data including book equity, net income, and total assets are obtained from Standard \& Poor's Investment Services' Compustat North America ("COMPUSTAT") database for the period 1962 to 2009. The data sample excludes stocks with share prices below $\$ 5$. 
To ensure the accounting information is known at the time market equity value is computed, I match CRSP and COMPUSTAT records using the approach documented in Fama and French (1992). Annual accounting data for all firms with fiscal years ending in calendar year $t-1$ are matched with price information for the 12 months from July at time $t$ to June at time $t+1 .^{2}$ To be included in the sample, firms are required to have valid prices at December of year $t-1$ and June of year $t$ and must have at least 2 years of prior history in the COMPUSTAT database. To avoid selection bias, accounting variables prior to 1962 are excluded from the sample.

From this data sample, I retain observations with non-missing values for the variables which are required to estimate residual firm value. $R F V$ is estimated as the residual from monthly, within-industry, cross-sectional regressions following the specification in equation 2.2. Market equity $(M E)$ is computed monthly as the product of price and the number of shares outstanding (in millions). Book equity $(B E)$ is computed as total common equity (item ceq) plus deferred taxes (item txditc). If total common equity is missing, BE is set to missing for that year. Net Income $(N I)$ is selected directly from COMPUSTAT (item ni). Book Leverage $(B L E V)$ is computed as one minus book equity divided by book value of total assets $(1-B E / T A)$. To ensure the estimates of $R F V$ are not influenced by extremely illiquid stocks, stocks are required to have strictly positive trading volume and a valid measure of Amihud's (2002) measure of illiquidity. Stocks are also required to have non-missing monthly returns over the prior 12 months. Similar to RKRV, firms with market equity below $\$ 10$ million are also excluded. All tables are based on the period 1967 to 2010 as some industries do not have sufficient observations to reliably estimate residual firm value over the 1963 to 1966 period. To minimize the influence of extreme values, scaled variables are winsorized at the 1st and 99th percentiles.

\footnotetext{
${ }^{2}$ The Fama and French (1992) approach is used to ensure that arbitrageurs are able to observe the accounting data at the time of trade. The use of quarterly accounting data and/or more timely matching of market equity provides similar results.
} 


\section{Table 3.1}

Descriptive Statistics (1967-2010)

This table presents time-series averages of monthly cross-sectional summary statistics for various stock characteristics. The sample consists of common stocks listed on NYSE, AMEX, and NASDAQ from January 1967 to December 2010. Additional details regarding the data sample and key variables are contained in Section 3.1. Panel A reports descriptive statistics for the key variables. Panel B reports time-series averages of monthly pairwise cross-sectional correlations. Panel C reports descriptive statistics for firms within each of the Fama and French 12 industry classifications. $M B E$ is the market to book equity ratio. $M B E-I A$ is the industry-adjusted market to book equity ratio where industry is defined using 2-digit SIC codes. $M B A-I A$ is the industry-adjusted market to book assets ratio where industry is defined using 2-digit SIC codes. $R F V$ is residual firm value estimated using cross-sectional valuation regressions within each of the Fama and French 12 industry classifications detailed in Section 3.3. $M E$ is market value of equity, $B E$ is book value of equity, $N I$ is net income, $B L E V$ is book leverage, $R E T 1 M$ is the past one-month return (includes delisting return), and $R E T 6 M$ is the past 6-month return. Dollar values are in millions. Ratios are winsorized at the 1st and 99th percentiles.

\begin{tabular}{|c|c|c|c|c|c|c|c|c|c|c|c|c|}
\hline \multicolumn{13}{|c|}{ Panel A: Descriptive Statistics } \\
\hline Variable & MEAN & MED & STD & MIN & MAX & $\mathrm{P} 1$ & $\mathrm{P} 25$ & P75 & P99 & & & \\
\hline$M B E$ & 2.631 & 1.665 & 3.03 & 0.33 & 23.06 & 0.38 & 1.09 & 2.86 & 17.36 & & & \\
\hline$M B E-I A$ & -0.052 & -0.258 & 0.79 & -0.92 & 4.19 & -0.87 & -0.53 & 0.13 & 3.75 & & & \\
\hline$M B A-I A$ & -0.022 & -0.127 & 0.57 & -0.75 & 2.95 & -0.68 & -0.35 & 0.07 & 2.60 & & & \\
\hline$R F V$ & 0.000 & -0.024 & 0.60 & -2.43 & 2.90 & -1.41 & -0.37 & 0.33 & 1.64 & & & \\
\hline$M E$ & 1856 & 279 & 7370 & 9 & 158180 & 15 & 91 & 1005 & 30918 & & & \\
\hline$B E$ & 842 & 151 & 3127 & 1 & 66183 & 5 & 52 & 510 & 11872 & & & \\
\hline$N I$ & 92 & 13 & 508 & -7573 & 10307 & -193 & 3 & 54 & 1708 & & & \\
\hline$B L E V$ & 0.519 & 0.511 & 0.22 & 0.09 & 0.95 & 0.09 & 0.36 & 0.67 & 0.95 & & & \\
\hline$R E T 1 M$ & 0.012 & 0.006 & 0.11 & -0.50 & 0.91 & -0.24 & -0.05 & 0.06 & 0.33 & & & \\
\hline RET6M & 0.102 & 0.059 & 0.32 & -0.67 & 4.44 & -0.43 & -0.08 & 0.22 & 1.18 & & & \\
\hline \multicolumn{13}{|c|}{ Panel B: Pearson Correlations } \\
\hline & $M B E$ & $M B E-I A$ & $M B A-I A$ & $R F V$ & $M E$ & $B E$ & $N I$ & $B L E V$ & $R E T 1 M$ & & & \\
\hline$M B E-I A$ & 0.83 & & & & & & & & & & & \\
\hline$M B A-I A$ & 0.76 & 0.86 & & & & & & & & & & \\
\hline$R F V$ & 0.64 & 0.67 & 0.64 & & & & & & & & & \\
\hline$M E$ & 0.08 & 0.08 & 0.08 & 0.16 & & & & & & & & \\
\hline$B E$ & -0.06 & -0.04 & -0.04 & 0.04 & 0.80 & & & & & & & \\
\hline$N I$ & 0.00 & 0.01 & 0.01 & 0.06 & 0.80 & 0.79 & & & & & & \\
\hline$B L E V$ & -0.06 & 0.05 & -0.15 & 0.00 & 0.00 & 0.03 & 0.02 & & & & & \\
\hline$R E T 1 M$ & 0.08 & 0.08 & 0.08 & 0.13 & 0.01 & 0.00 & 0.00 & 0.00 & & & & \\
\hline RET6M & 0.20 & 0.19 & 0.18 & 0.25 & 0.00 & -0.02 & -0.02 & 0.01 & 0.39 & & & \\
\hline \multicolumn{13}{|c|}{ Panel C: Industry Statistics (Fama and French 12 groups) } \\
\hline FF12IND & CNDUR & CDUR & MANU & ENER & CHEM & COMP & TELTV & UTIL & WHOL & MED & FIN & OTHER \\
\hline Count & 170 & 75 & 348 & 85 & 71 & 295 & 47 & 142 & 236 & 151 & 358 & 253 \\
\hline Min & 78 & 26 & 113 & 17 & 33 & 20 & 13 & 93 & 36 & 16 & 21 & 55 \\
\hline Max & 243 & 125 & 506 & 134 & 96 & 670 & 85 & 191 & 383 & 334 & 761 & 420 \\
\hline$M E$ & 2050 & 1216 & 1302 & 3969 & 2786 & 2039 & 5315 & 1796 & 1466 & 2442 & 1590 & 1291 \\
\hline$B E$ & 655 & 811 & 551 & 2277 & 947 & 549 & 3666 & 1536 & 513 & 550 & 904 & 712 \\
\hline$N I$ & 105 & 81 & 65 & 277 & 139 & 65 & 204 & 119 & 66 & 90 & 104 & 53 \\
\hline$B L E V$ & 0.46 & 0.47 & 0.47 & 0.47 & 0.47 & 0.40 & 0.55 & 0.61 & 0.50 & 0.38 & 0.80 & 0.51 \\
\hline
\end{tabular}


Table 3.1, Panel A presents time-series averages of cross-sectional descriptive statistics of the data sample for the period 1967 to 2010. The data sample represents 1,178,575 observations and 11,997 unique securities. Residual Firm Value, $R F V$, the primary measure of relative misvaluation, is mean zero since it is estimated as the residual from within-industry valuation regressions. The sample exhibits variation in measures of relative value such as the market-to-book equity ratio $(M B E)$, as well as measures of relative misvaluation such as $R F V$, the industry-adjusted marketto-book equity ratio $(M B E-I A)$, and the market-to-book assets ratio $(M B A-I A)$. Market equity, book equity, and net income are skewed and thus log values will be used in the valuation regressions.

Table 3.1, Panel B presents the Pearson pairwise correlation coefficients for the data sample. $R F V$ is positively correlated with other measures of relative misvaluation, such as $M B E-I A(0.67)$ and $M B A-I A(0.64)$. $M E$ is highly correlated with both $B E$ and $N I$. The correlation between $B E$ and $N I$ is also high at 0.79 , but does not influence the estimation of $R F V .^{3}$

Table 3.1, Panel C presents average firm counts and summary statistics for each of the 12 industry groups for the sample period 1967 to 2010. Minimum firm-month counts are important as $R F V$ is estimated using within-industry cross-sectional regressions. Only three of the industries have minimum industry-month firm counts below 20 observations. There are 48 industry-month combinations with 20 or fewer firm observations in the data sample. Each of these 48 industry-month combinations occur prior to 1970. Sub-period analysis in later tables demonstrates that the industry-month combinations with less than 20 firms do not materially affect the results. In untabulated results, I find substantial variation across industries for a wide

${ }^{3}$ In untabulated results $N I^{+}$is replaced with $N I / B E^{+}$in the valuation regressions to see if the high correlation of net income and book equity variables affects the results. The adjusted R-square values are almost identical to those in the above specification and there is not a significant change in the ranking of firms according to relative misvaluation. Further, analysis in later tables using $\mathrm{RFV}$ based on the model with $\mathrm{NI}^{+}$is quantitatively similar to the model with $N I / B E^{+}$. I thus continue with RKRV's specification for the remainder of the paper. 
range of accounting-based measures such as price-to-earnings multiple (12.9 to 22.5), book leverage (0.38 to 0.80$)$, asset growth (0.095 to 0.244 ), and cash flow growth (-0.019 to 0.149) providing support for performing valuation regressions within each of the industry groups.

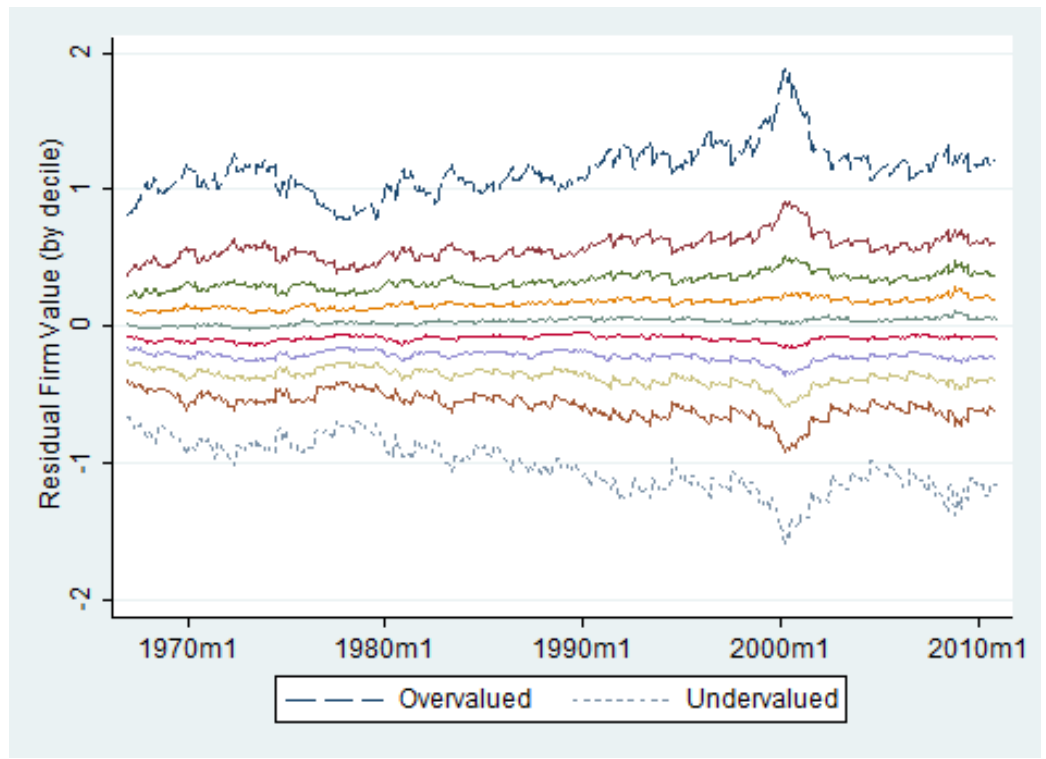

Fig. 3.1. Residual Firm Value (Jan. 1967 to Dec. 2010)

This figure shows monthly estimates of residual firm value (RFV) for the period 1967 to 2010. $\mathrm{RFV}$ is the residual from monthly within-industry, cross-sectional regressions where the dependent variable is $\log$ market equity and the independent variables are $\log$ book equity, $\log$ absolute value of net income, a negative net income indicator interacted with log absolute value of net income, and book leverage. Each month, firms are sorted into deciles based on RFV. The equal-weighted average RFV is calculated monthly for each decile portfolio and displayed in this figure.

Figure 3.1 presents the time series of monthly average $R F V$ for the firms within each $R F V$ decile. Decile 9 represents firms that are most undervalued (negative $R F V)$ and decile 0 represents firms that are most overvalued. Firms are sorted in this manner as relatively undervalued firms are expected to have higher average returns than relatively overvalued firms, all else equal. By definition average monthly $R F V$ equals zero for each industry. The spread in average $R F V$ between the lowest and highest deciles demonstrates significant variation across time. 


\subsection{Portfolio Results}

$R F V$ Portfolios. The first empirical tests investigate whether $R F V$ predicts returns in the cross-section of stock returns. If $R F V$ captures security mispricing and/or cross-sectional differences in expected returns, then relatively undervalued stocks should have higher average returns than relatively overvalued stocks. $R F V$ portfolios are formed by sorting stocks into decile portfolios according to $R F V$ estimated during month $t-2$. The decile rankings are reversed so that relatively undervalued stocks (lowest $R F V$ ) are placed in decile 9 and relatively overvalued stocks (highest $R F V)$ are placed in decile 0 . Portfolios are held for one month at time $t$. One month is skipped between the measurement period and holding period to minimize microstructure issues.

Table 3.2 confirms that $R F V$ has predictive power in the cross-section of stocks. Panel A shows that average time $t$ returns are increasing across $R F V$ deciles. Relatively undervalued stocks (decile 9) have average future returns that are approximately 48 basis points $(t$-statistic $=2.47)$ per month higher than returns to relatively overvalued stocks (decile 0) over the period 1967 to 2010. Table 3.2, Panel B shows that market model alphas average 0.56 basis points $(t$-statistic $=2.87) .{ }^{4}$ These results suggest that $R F V$ is a reasonable proxy for the direction of arbitrage trades.

As discussed earlier, Figure 3.1 shows that the difference in RFV between relatively undervalued and relatively overvalued stocks exhibits substantial variation across time. Intuitively this makes sense as relative misvaluation, whether driven by mispricing or cross-sectional differences in expected returns, is likely to vary across time with changes in the business cycle or time-varying limits-to-arbitrage. Cooper,

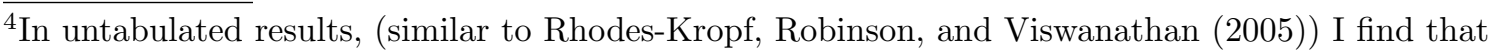
intrinsic value-to-book (Value/Book) estimated from the market-to-book decomposition (e.g. valuation regressions) does not predict returns in the cross-section of stocks. The difference in average returns between high and low Value/Book decile portfolios is approximately 28 basis points per month $(t$-statistic $=1.35)$ over the period 1967 to 2010. Consistent with Daniel and Titman (2006) these results suggest that $R F V$ isolates the common, intangible components of $M B E, M B E-I A$, and $M B A-I A$ that are responsible for the ability to predict returns in the cross-section of stocks.
} 
Table 3.2

Relative Misvaluation Portfolio Returns (1967-2010)

This table presents time series average returns (in \% form) to portfolios formed on a proxy of relative misvaluation for the period 1967 to 2010 and indicated sub-periods. Residual firm value (" $R F V$ "), the proxy for relative misvaluation, is computed as the residual from within-industry cross sectional valuation regressions. The construction of $R F V$ is detailed in Section 2.3. Panel A reports the one-month $($ time $=t)$ holding period returns to portfolios formed by sorting stocks into deciles each month according to relative misvaluation estimated at time $t-2$. One-month is skipped between the measurement period and calculation of holding period returns to minimize microstructure issues. Portfolios are sorted such that stocks in portfolio 9 are the most undervalued ( $R F V$ is lowest) while the firms in portfolio 0 are the most overvalued ( $R F V$ is highest). Panel $\mathrm{B}$ reports alphas computed using the market model for the portfolios in Panel A. Panel C reports the returns to the relative misvaluation portfolios when the cumulative market return over the most recent 36 month period is greater than or equal to zero (Up) and when the cumulative market return is negative (Down). T-statistics reported below coefficient estimates are based on Newey-West standard errors.

\begin{tabular}{|c|c|c|c|c|c|c|c|c|c|c|c|c|}
\hline & & \multicolumn{11}{|c|}{ Portfolio Decile } \\
\hline & & 0 & 1 & 2 & 3 & 4 & 5 & 6 & 7 & 8 & 9 & $9-0$ \\
\hline \multicolumn{13}{|c|}{ Panel A: Average Returns (\%) to Relative Misvaluation Portfolios } \\
\hline \multirow{2}{*}{\multicolumn{2}{|c|}{$R F V$}} & 0.87 & 1.02 & 1.01 & 1.12 & 1.11 & 1.23 & 1.32 & 1.36 & 1.33 & 1.35 & 0.48 \\
\hline & & 2.93 & 3.93 & 4.18 & 4.84 & 4.82 & 5.32 & 5.40 & 5.39 & 4.80 & 4.39 & 2.47 \\
\hline \multicolumn{13}{|c|}{ Panel B: Market Model Alphas (\%) to Relative Misvaluation Portfolios } \\
\hline \multirow{2}{*}{\multicolumn{2}{|c|}{$R F V$}} & -0.18 & 0.04 & 0.06 & 0.20 & 0.22 & 0.34 & 0.41 & 0.43 & 0.39 & 0.38 & 0.56 \\
\hline & & -1.49 & 0.35 & 0.54 & 1.80 & 1.92 & 2.76 & 2.96 & 3.14 & 2.54 & 2.07 & 2.87 \\
\hline \multicolumn{13}{|c|}{ Panel C: Average Returns (\%) following Up and Down Markets } \\
\hline \multirow[t]{4}{*}{$R F V$} & $\mathrm{Up}$ & 0.81 & 0.94 & 0.91 & 1.02 & 1.01 & 1.11 & 1.19 & 1.21 & 1.17 & 1.13 & 0.32 \\
\hline & & 2.66 & 3.63 & 3.81 & 4.39 & 4.59 & 4.90 & 5.00 & 4.87 & 4.35 & 3.81 & 1.56 \\
\hline & Down & 1.14 & 1.44 & 1.47 & 1.62 & 1.60 & 1.84 & 1.99 & 2.10 & 2.13 & 2.44 & 1.30 \\
\hline & & 1.46 & 1.90 & 2.14 & 2.49 & 2.21 & 2.68 & 2.78 & 2.84 & 2.52 & 2.64 & 3.08 \\
\hline
\end{tabular}


Gutierrez, and Hameed (2004, "CGH") show that on average momentum strategies are profitable (not profitable) when the most recent 36-month market return is non-negative (negative). They argue that mispricing is correlated with the market state.

Table 3.2, Panel $\mathrm{C}$ demonstrates time-variation in misvaluation as returns to a long-short $R F V$ hedge portfolio (9-0) are higher in periods when the most recent 36 -month market return is negative ("Down") $(1.30 \%$ per month, $t$-statistic=3.08) than in periods when the most recent 36-month market return is non-negative ("Up") $(0.32 \%, t$-statistic $=1.56)$. This finding is consistent with the suggested interaction of momentum traders and arbitrageurs. All else equal, I expect arbitrage strategies to be less profitable when arbitrageurs reduce arbitrage intensity in response to observing past returns that suggest momentum traders will continue to push prices away from fundamental value. Likewise, it seems reasonable that the intensity of momentum trades will decrease during periods when momentum trading is unprofitable (e.g. Shleifer and Vishny (1997)) and the intensity and effectiveness of arbitrageur capital will increase as a result.

Momentum and RFV Portfolios. I next examine the interaction of relative misvaluation and momentum strategy returns. Portfolio sorts on past returns (deciles) followed by dependent sorts on $R F V$ (terciles) demonstrate that relatively undervalued stocks produce significantly higher returns than relatively overvalued stocks in each of the momentum deciles over the period 1967 to 2010. Table 3.3, Panel A presents average returns to momentum portfolios conditioned on $R F V$. Firms in $R F V 3$ are relatively undervalued and $R F V 1$ are relatively overvalued. Returns to $R F V$ spread portfolios (relatively undervalued stocks minus relatively overvalued stocks) are positive and significant within each momentum decile with average returns of 0.25 to $0.71 \%$ per month ( $t$-statistics range from 1.77 to 4.53$)$ with stronger results in the past winners decile. Thus $R F V$ appears to be a reasonable proxy for the direction of arbitrage trade across each momentum decile. 
Table 3.3

Momentum and Relative Misvaluation Portfolios (1967-2010)

This table presents time series average returns (in \% form) to portfolios formed on past returns and relative misvaluation for the period 1967 to 2010 (Panel A) and the sub-period 1993 to 2010 (Panel B). Portfolios are formed monthly by first sorting stocks into decile portfolios according to past 6 month returns. Firms are then placed (dependent sort) into three relative misvaluation tercile portfolios based on residual firm value $(R F V)$. The construction of $R F V$ is detailed in Section 2.3. $R F V 1$ portfolios contain firms with $R F V$ values in the highest tercile (relatively overvalued) and $R F V 3$ contains firms with $R F V$ values in the lowest tercile (relatively undervalued). Onemonth holding period returns are calculated for each portfolio. One month is skipped between measurement of sorting variables and computing holding period returns to minimize microstructure issues. T-statistics reported below coefficient estimates are based on Newey-West standard errors.

\begin{tabular}{|c|c|c|c|c|c|c|c|c|c|c|c|}
\hline Momentum Decile & 0 & 1 & 2 & 3 & 4 & 5 & 6 & 7 & 8 & 9 & $9-0$ \\
\hline \multicolumn{12}{|c|}{ Panel A: Average returns (\%) for portfolios sorted on MOM (deciles) then $R F V$ (terciles) } \\
\hline \multirow[t]{2}{*}{$R F V 1$} & 0.31 & 0.72 & 0.95 & 0.93 & 0.95 & 0.97 & 0.98 & 0.97 & 1.17 & 1.35 & 1.05 \\
\hline & 0.87 & 2.48 & 3.71 & 3.72 & 4.10 & 4.07 & 4.20 & 3.90 & 4.26 & 3.94 & 4.40 \\
\hline \multirow[t]{2}{*}{$R F V 2$} & 0.71 & 1.13 & 1.22 & 1.15 & 1.27 & 1.21 & 1.09 & 1.15 & 1.21 & 1.75 & 1.04 \\
\hline & 2.16 & 3.96 & 4.94 & 4.80 & 5.92 & 5.84 & 5.14 & 4.93 & 4.76 & 5.51 & 4.07 \\
\hline \multirow[t]{2}{*}{$R F V 3$} & 0.56 & 1.15 & 1.31 & 1.26 & 1.35 & 1.51 & 1.45 & 1.58 & 1.69 & 2.06 & 1.50 \\
\hline & 1.63 & 3.72 & 4.76 & 4.68 & 5.25 & 6.04 & 5.65 & 6.19 & 5.95 & 6.20 & 5.84 \\
\hline \multirow[t]{2}{*}{$R F V 3-R F V 1$} & 0.25 & 0.43 & 0.36 & 0.33 & 0.40 & 0.54 & 0.47 & 0.62 & 0.52 & 0.71 & 0.45 \\
\hline & 1.77 & 3.69 & 3.00 & 2.88 & 3.26 & 4.39 & 3.81 & 4.53 & 3.45 & 3.92 & 2.40 \\
\hline \multicolumn{12}{|c|}{ Panel B: Average returns (\%) for 1993 to 2010 Sub-Period } \\
\hline \multirow[t]{2}{*}{$R F V 1$} & 0.35 & 0.59 & 0.75 & 0.82 & 0.82 & 0.84 & 0.85 & 0.74 & 0.99 & 1.16 & 0.81 \\
\hline & 0.65 & 1.39 & 1.95 & 2.39 & 2.63 & 2.59 & 2.70 & 2.20 & 2.53 & 2.15 & 1.94 \\
\hline \multirow[t]{2}{*}{$R F V 2$} & 0.70 & 0.91 & 1.11 & 0.92 & 1.08 & 1.02 & 1.03 & 1.13 & 1.08 & 1.79 & 1.09 \\
\hline & 1.40 & 2.24 & 3.00 & 2.66 & 3.51 & 3.27 & 3.25 & 3.49 & 2.93 & 3.54 & 2.23 \\
\hline \multirow[t]{2}{*}{$R F V 3$} & 0.52 & 0.99 & 1.20 & 1.10 & 1.08 & 1.25 & 1.23 & 1.46 & 1.60 & 2.25 & 1.73 \\
\hline & 0.90 & 2.16 & 2.81 & 2.72 & 2.69 & 3.34 & 3.17 & 3.70 & 3.72 & 3.98 & 3.37 \\
\hline \multirow[t]{2}{*}{$R F V 3-R F V 1$} & 0.17 & 0.40 & 0.45 & 0.28 & 0.26 & 0.41 & 0.39 & 0.73 & 0.61 & 1.10 & 0.92 \\
\hline & 0.68 & 2.15 & 2.41 & 1.55 & 1.35 & 2.48 & 2.00 & 3.50 & 2.73 & 3.33 & 2.93 \\
\hline
\end{tabular}


Average returns to long-short momentum portfolios are positive and significant across $R F V$ portfolios. For relatively overvalued firms ( $R F V 1)$, the average return to a long-short momentum portfolio is $1.05 \%(t$-statistic $=4.40)$ per month while the average return to relatively undervalued firms $(R F V 3)$ is $1.50 \%$ ( $t$-statistic $=5.84)$. The momentum strategy constructed using relatively undervalued firms outperforms the strategy using relatively overvalued firms by approximately 45 basis points per month. As momentum is profitable in both strategies it seems reasonable that some momentum traders may trade unconditionally with respect to relative valuation of the underlying stocks.

Table 3.3, Panel B presents average returns to momentum portfolios conditioned on $R F V$ for the 1993 to 2010 sub-period. Similar to the full-period sample, the $R F V$ spread portfolio is positive within each momentum decile (significant in 7 of the 10 deciles) with larger differences in the past winners momentum deciles. The highly significant differences in spreads between relatively undervalued and relatively overvalued past winner portfolios is consistent with relative misvaluation being an important dimension of the profitability of the momentum strategy. Summarizing the portfolio sorts, I find that relatively undervalued firms have higher future returns than overvalued firms, especially for past winners. As such, it seems reasonable that $R F V$ proxies for the direction of arbitrage trades.

Figure 3.2 shows that there is substantial variation in $R F V$ within momentum stocks classified as past winners (Panel A) and past losers (Panel B). The graphed lines represent average $R F V$ for tercile portfolios formed monthly by sorting stocks on $R F V$ within each momentum decile. The graph suggests that at least one-third of the stocks in each of the past winners and past losers deciles are overvalued $(R F V>0))$ and one-third are undervalued $(R F V<0)$. This is consistent with Fama's (1998) assertion that in an efficient market one expects to observe underreaction and overreaction with similar frequencies. The magnitude of misvaluation appears to be stronger in the overvalued winner and undervalued loser portfolios. 

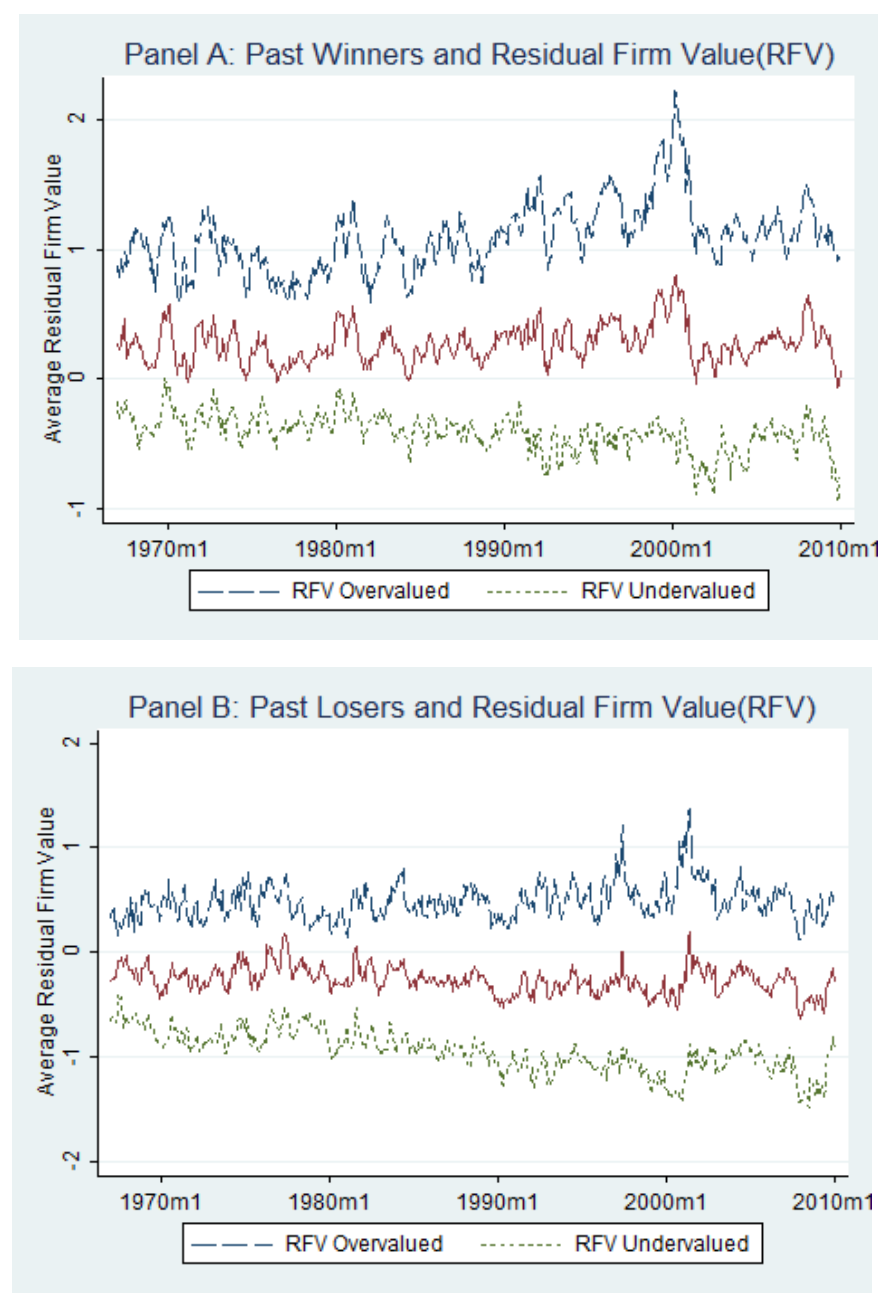

Fig. 3.2. Residual Firm Value of Winners and Losers (Jan. 1967 to Dec. 2010)

This figure shows monthly estimates of residual firm value (RFV) for the period 1967 to 2010 for stocks that are recent winners (Panel A) and recent losers (Panel B). RFV is the residual from monthly within-industry, cross-sectional regressions where the dependent variable is $\log$ market equity and the independent variables are $\log$ book equity, $\log$ absolute value of net income, a negative net income indicator interacted with log absolute value of net income, and book leverage. Each month, firms are sorted into deciles based on RFV. The equal-weighted average RFV is calculated monthly for each decile portfolio and displayed in this figure.

This is consistent with more mispricing as arbitrageurs reduce arbitrage intensity when they expect momentum traders to purchase overvalued winners and sell undervalued losers, pushing prices away from fundamental value. 


\subsection{Regression Results}

In this section I follow Fama-MacBeth (1973, FMB) and estimate FMB regressions using individual stocks. Regression analysis allows the estimation of the marginal effects of residual firm value after controlling for a wide range of stock characteristics. Based on the discussions above, I expect to find a negative and significant relationship between $R F V$ and future returns. If $R F V$ proxies for the direction of arbitrageur trades, then the relationship between $R F V$ and future returns should not be subsumed by cross-sectional differences in firm characteristics and other control variables.

The dependent variable in the FMB regressions is time $t$ excess stock returns. Independent variables are measured at time $t-2$. One month is skipped between measurement of the dependent and independent variables to minimize microstructure issues. Control variables motivated by Brennan, Chordia and Subrahmanyam (1998) include book-to-market (B/M), market equity (SIZE), turnover (TURN), and one-month past returns (RET1M, measured at t-2), and past returns (RET212M, measured over t-3 to t-13). ${ }^{5}$ Based on the findings of Amihud (2002), I control for illiquidity (ILLIQ). I also control for idiosyncratic volatility (IVOL) as suggested by Ang, Hodrick, Xing, and Zhang (2006).

Asparouhova, Bessembinder, and Kalcheva (2010, ABK) show that microstructure noise can result in an upward biased estimate of return premia when illiquid stocks are included in the sample. They suggest that using realized returns as a dependent variable and firm measures correlated with microstructure noise as independent variables may lead to upward biased estimates. Since $R F V$ is computed as the residual obtained by regressing market value on accounting variables, it seems

\footnotetext{
${ }^{5}$ Atkins and Dyl (1997) provide evidence that NASDAQ stock volumes are overstated due to interdealer trading. In untabulated results I run two tests to ensure that the results are not due to improper measurement of TURN. First, I exclude NASDAQ stocks from the FMB regressions. Next, following Avramov and Chordia (2006) I separate NASDAQ volume from NYSE and AMEX volume and include a NASDAQ dummy. In both cases I do not find a material change in the coefficient estimates on $R F V$.
} 
reasonable to expect that $R F V$ may be correlated with microstructure noise. I address this risk of microstructure noise in the regression analysis by skipping one month between the dependent and independent variables. In untabulated results, I also follow the suggestions of ABK and use weighted least squares (WLS) where the weight is set equal to one plus the prior month's gross return. There are no material differences in the results obtained using WLS so I report the OLS results in Table 3.4 .

Table 3.4, Panel A shows the results from FMB regressions using individual stocks where the dependent variable is the excess stock return (in excess of the riskfree rate). The independent variables are residual firm value $(R F V)$ and the control variables discussed above. The first column shows the coefficient estimates using all stocks and the control variables. As documented in the literature, I find a positive and significant relationship between future returns and the book-to-market ratio, past returns, and illiquidity. While the literature has documented a negative and significant relationship between future returns and firm size, the coefficient estimate in this regression is positive and insignificant. This is due to the high correlation between firm size and illiquidity. When illiquidity is excluded as a control, the coefficient estimate on firm size is negative and highly significant. The first column also shows that the coefficient estimate on idiosyncratic volatility is negative and highly significant.

In the second column, I include $R F V$ in the regression using all stocks in the data sample. Similar to the results of the portfolio sorts, there is a significant negative relationship between future returns and residual firm value with a coefficient estimate of $-0.30 \%(t$-statistic $=-4.70)$ for the period 1967-2010. Relatively undervalued firms have higher average returns than relatively overvalued firms, all else equal. The only significant change in the control variables is the loading on the book-to-market variable which is not statistically significant in this regression. Fama and French (1992) and many others have demonstrated the cross-sectional predictability of the book- 
Table 3.4

Fama-MacBeth Regressions using Individual Stocks (1967-2010)

This table presents the results of Fama-MacBeth (FMB) regressions where the dependent variable is excess returns to individual stocks and the independent variables are residual firm value, $R F V$, and stock characteristics. One-month is skipped between measurement of the dependent $(t)$ and independent $(t-2)$ variables to minimize microstructure effects. The construction of $R F V$ is detailed in Section 2.3. The control variables are defined in Section 3.3. Individual stocks are sorted into momentum quintile groups based on their prior six month compound return (MOM5 represents past winners, MOM1 represents past losers). Each panel reports results for the full-sample as well as each of the momentum quintile groups. Panel A reports FMB coefficient estimates for the sample period 1967 to 2010 . Panel B reports FMB coefficient estimates over the 1967 to 1992 and 1993 to 2010 sub-periods. Panel C reports FMB coefficient estimates in periods following Up markets (prior 36-month market return is greater than or equal to zero) and Down markets. Coefficient estimates are multiplied by 100. T-statistics reported below coefficient estimates are based on Newey-West standard errors.

\begin{tabular}{|c|c|c|c|c|c|c|c|}
\hline \multicolumn{8}{|c|}{ Panel A: FMB coefficient estimates (1967-2010) } \\
\hline & \multicolumn{2}{|c|}{ All Firms } & MOM1 & MOM2 & MOM3 & MOM4 & MOM5 \\
\hline \multirow[t]{2}{*}{$R F V$} & & -0.30 & -0.22 & -0.20 & -0.36 & -0.41 & -0.45 \\
\hline & & -4.70 & -2.33 & -2.39 & -4.13 & -4.54 & -4.69 \\
\hline \multirow[t]{2}{*}{$\ln (B / M)$} & 0.21 & 0.05 & 0.16 & 0.16 & 0.03 & -0.03 & -0.08 \\
\hline & 2.89 & 0.60 & 1.61 & 1.77 & 0.29 & -0.29 & -0.71 \\
\hline \multirow[t]{2}{*}{$\ln (S I Z E)$} & 0.08 & 0.11 & 0.27 & 0.04 & 0.10 & -0.02 & 0.00 \\
\hline & 1.28 & 1.66 & 2.66 & 0.40 & 1.64 & -0.28 & 0.01 \\
\hline \multirow[t]{2}{*}{$\ln (I L L I Q)$} & 0.19 & 0.20 & 0.21 & 0.08 & 0.20 & 0.12 & 0.20 \\
\hline & 3.78 & 3.79 & 2.61 & 1.09 & 3.39 & 1.70 & 2.47 \\
\hline \multirow[t]{2}{*}{$\ln (T U R N)$} & 0.11 & 0.11 & 0.09 & 0.05 & 0.11 & 0.00 & 0.01 \\
\hline & 1.41 & 1.42 & 0.83 & 0.53 & 1.50 & -0.03 & 0.13 \\
\hline \multirow[t]{2}{*}{$R E T 1 M$} & 1.19 & 1.13 & -0.47 & -0.22 & 0.80 & 1.28 & 1.84 \\
\hline & 3.69 & 3.32 & -1.00 & -0.43 & 1.52 & 2.28 & 4.51 \\
\hline \multirow[t]{2}{*}{$R E T 2-12 M$} & 0.79 & 0.80 & 0.86 & 0.82 & 0.84 & 0.99 & 0.66 \\
\hline & 5.21 & 5.07 & 3.47 & 2.90 & 3.83 & 4.38 & 4.98 \\
\hline \multirow[t]{2}{*}{$I V O L$} & -27.13 & -27.11 & -36.35 & -25.12 & -28.58 & -11.46 & -24.46 \\
\hline & -7.19 & -7.12 & -8.32 & -4.64 & -5.36 & -1.99 & -4.39 \\
\hline \multirow[t]{2}{*}{ Intercept } & 1.54 & 1.34 & 0.46 & 1.27 & 1.41 & 1.25 & 1.70 \\
\hline & 3.21 & 2.85 & 0.87 & 2.55 & 2.98 & 2.60 & 3.18 \\
\hline$A d j .-R^{2}$ & 5.84 & 6.00 & 5.27 & 5.92 & 6.30 & 6.39 & 5.45 \\
\hline
\end{tabular}

Panel B: FMB coefficient estimates in indicated sub-periods

\begin{tabular}{rrrrrrrr}
\multirow{2}{*}{$1967-1992$} & \multicolumn{1}{c}{ All Firms } & & MOM1 & MOM2 & MOM3 & MOM4 & MOM5 \\
\cline { 2 - 2 } \cline { 5 - 7 } $1993-2010$ & -0.34 & & -0.23 & -0.25 & -0.44 & -0.47 & -0.44 \\
& -4.74 & & -1.75 & -2.24 & -4.21 & -3.86 & -3.82 \\
& -0.23 & & -0.21 & -0.13 & -0.24 & -0.33 & -0.47 \\
& -2.08 & & -1.57 & -1.00 & -1.69 & -2.47 & -2.81 \\
\hline
\end{tabular}

Panel C: FMB coefficient estimates following up and down markets

\begin{tabular}{lrrrrrrr}
\multirow{2}{*}{ Mkt $-U p$} & \multicolumn{1}{c}{ All Firms } & & MOM1 & MOM2 & MOM3 & MOM4 & MOM5 \\
\cline { 2 - 2 } Mkt - Down & -0.29 & & -0.19 & -0.21 & -0.35 & -0.38 & -0.48 \\
& -4.11 & & -1.91 & -2.24 & -3.44 & -3.73 & -4.50 \\
& -0.34 & & -0.40 & -0.15 & -0.40 & -0.55 & -0.29 \\
\hline \hline
\end{tabular}


to-market ratio. Since $R F V$ is estimated using a market-to-book decomposition, I infer that $R F V$ contains the information in the book-to-market ratio that predicts returns in the cross-section. These results support the findings of Daniel and Titman (2006), who show that return predictability is related to intangible information contained in the book-to-market ratio, as captured by $R F V$, and not related to tangible accounting information.

Table 3.4, Panel A also reports results in which firms are sorted into quintile portfolios based on past returns measured over time t- 7 to t-2 (denoted $M O M 1$ to MOM5, MOM5 represents past winners). FMB regressions using individual stocks are estimated within each of the momentum quintile portfolios. The coefficient estimates on $R F V$ are negative and significant in each of the momentum quintiles, but are stronger in the past winners quintile $(-0.45 \%, t$-statistic $=-4.69)$. While still negative and significant, the coefficient estimate in past losers (MOM1) quintile ($0.22 \%, t$-statistic $=-2.33)$ is approximately one-half the size of the past winners quintile.

Table 3.4, Panel B shows that the coefficient estimates on $R F V$ are significant in both the 1967 to $1992(-0.34 \%, t$-statistic=-4.74) and 1993 to $2010(-0.23 \%, t$ statistic $=-2.08)$ sub-periods. The results are highly significant in the past winners deciles in both sub-periods. Similar to the full-period results, the coefficient estimates on $R F V$ in the past losers quintile is roughly one-half the size of the coefficient estimates in the past winners quintile. Table 3.4, Panel $\mathrm{C}$ shows that the results are also significant in periods following up markets $(-0.29 \%, t$-statistic $=-4.11)$ and in periods following down markets $(-0.34 \%, t$-statistic $=-2.37)$. The results are strongest in the past winners quintile following Up markets and in the MOM4 quintile following down markets.

Overall, $R F V$ appears to be a reasonable proxy for the direction of arbitrage trades. Consistent with the portfolio analysis section, future returns are negative and significantly related to $R F V$. Relatively undervalued stocks have significantly 
higher returns than overvalued stocks. This relationship is robust to a full set of controls for firm characteristics, and is robust to regressions within sub-periods and market states. Similar to the portfolio analysis section, the relationship between future returns and $R F V$ is strongest in the past winners momentum quintile. 


\section{CONDITIONAL MOMENTUM STRATEGIES}

\subsection{Methodology}

In this section I use the interaction of momentum traders and arbitrageurs to motivate the construction of two conditional momentum strategies for empirical tests. Given the results of the portfolio analyses (Tables 3.2 and 3.3) and regression analyses (Table 3.4), it appears that there is a significant difference between the average returns of stocks that are relatively undervalued and those that are relatively overvalued, especially among past winners. Momentum strategies conditioned on the direction of arbitrage trades should result in at least partial separation of the effects of mispricing. Empirical tests using these conditional strategies should provide new insights into whether momentum is the result of behavioral or rational processes.

The return series to the unconditional momentum strategy, $M O M$, is computed each month by sorting firms into decile portfolios based on prior six month compound returns $(t-7$ to $t-2)$ and then holding the portfolio for six months $(t$ to $t+5)$. The monthly returns are computed as an equal-weighted average of the returns to the six overlapping portfolios (e.g. Jegadeesh and Titman (1993) and Liu and Zhang (2008)). One month is skipped between the measurement period and holding period to minimize microstructure effects. To demonstrate that the results in this section are not due to compound sorting on past returns, I construct an extreme unconditional momentum strategy (XMOM) using thirty groups (instead of deciles) when forming portfolios. ${ }^{1}$ The $X M O M$ strategy is thus constructed so that the long and short portfolios contain a similar number of firms as the conditional momentum strategies.

The interaction of arbitrageurs and momentum traders suggests that a conditional momentum strategy composed of stocks where momentum trades are in the same

\footnotetext{
${ }^{1}$ Bandarchuk and Hilscher (2012) show that sorting on firm characteristics such as size, turnover, price, credit risk, market-to-book, and illiquidity and then on past returns generates conditional momentum strategies that have more extreme past returns since the characteristics are correlated with past returns.
} 
direction as arbitrage trades should contain relatively less mispricing than a strategy formed using stocks where momentum trades are in the opposite direction of arbitrage trades. I construct the two conditional momentum strategies by sorting firms first into momentum deciles based on prior six month returns $(t-7$ to $t-2)$ and then into $R F V$ terciles as a proxy for the direction of arbitrage trades. ${ }^{2} A M O M$ is an arbitrage-reinforcing strategy that is long undervalued past winners (i.e. Table 3.3, $R F V 3, M O M 9)$ and short overvalued past losers (RFV1, MOM0). NMOM is an arbitrage-impeding strategy that is long overvalued past winners (RFV1, MOM9) and short undervalued past losers ( $R F V 3, M O M 0)$. I also construct a difference strategy, $N-A$, by subtracting the monthly $A M O M$ returns from $N M O M$ returns. While both $A M O M$ and NMOM may be related to omitted or time-varying risk, the interaction of arbitrageurs and momentum traders suggests that $N M O M$ contains relatively more mispricing than $A M O M .^{3}$ Thus, $N-A$ is designed to highlight the influence of mispricing on the unconditional momentum strategy.

Table 4.1, Panel A provides descriptive statistics for the momentum strategy, extreme momentum strategy, conditional momentum strategies, the risk factors from the Fama and French (1993) 3-factor model, and an Amihud (2002) illiquidity risk factor ("AMILS"). The mean return to the MOM strategy over the 1967 to 2010 period was $1.13 \%$ per month. The momentum strategy is clearly risky with a minimum monthly return of $-25.9 \%$ and a maximum monthly return of $31.1 \%$ over the 1967 to 2010 period. $A M O M$ has average monthly returns of $1.59 \%$ which is similar to $X M O M(1.53 \%)$ and more that twice as large as the return to NMOM $(0.77 \%)$.

\footnotetext{
${ }^{2}$ Each of the conditional momentum strategies are constructed using the $6 / 1 / 6$ portfolio methodology used to construct the $M O M$ strategy.

${ }^{3}$ It is important to note that I do not claim that $N M O M$ is all mispricing and $A M O M$ contains no mispricing. I simply claim that the arbitrage-impeding strategy contains relatively more mispricing than the arbitrage-reinforcing strategy. If mispricing confounds empirical tests of risk explanations, the arbitrage-reinforcing strategy should have a larger proportion of its profits explained as risk compensation relative to the arbitrage-impeding strategy.
} 
Table 4.1

Conditional Momentum Strategy Summary Statistics (1967-2010)

This table presents descriptive statistics (Panel A) and pairwise correlations (Panel B) for the set of (conditional) momentum strategies. $M O M$ represents returns to a portfolio that is long past winners $(\mathrm{MOM}$ decile $=9)$ and short past losers $(\mathrm{MOM}$ decile=0). Extreme momentum, XMOM, is similar to the formation of the momentum strategy that uses 30 portfolios instead of deciles. $A M O M$ represents returns to an arbitrage-reinforcing momentum strategy that is long undervalued past winners (RFV3, MOM9) and short overvalued past losers (RFV1, MOM0). NMOM represents returns to a arbitrage-impeding momentum strategy that is long overvalued past winners (RFV1, MOM9) and short undervalued past losers (RFV3, MOM0). Portfolios are formed monthly (based on returns measured during t-2 to t-7) and held for 6 months ( $t$ to $t+5$ ). One month is skipped between measurement period and calculation of holding period returns to minimize microstructure issues. Additional variables included are the components of Fama and French 3-factor model $(R M-R F, H M L$, and $S M B)$ and an Amihud (2002) return-based aggregate illiquidity risk factor $(A M I L S)$.

\begin{tabular}{|c|c|c|c|c|c|c|c|c|c|}
\hline \multicolumn{10}{|c|}{ Panel A: Descriptive Statistics } \\
\hline Variable & MEAN & MEDIAN & STD & MIN & MAX & $\mathrm{P} 1$ & $\mathrm{P} 25$ & P75 & P99 \\
\hline$M O M$ & 0.0113 & 0.0138 & 0.046 & -0.259 & 0.311 & -0.144 & -0.009 & 0.034 & 0.118 \\
\hline$X M O M$ & 0.0153 & 0.0167 & 0.059 & -0.378 & 0.411 & -0.164 & -0.009 & 0.046 & 0.148 \\
\hline$A M O M$ & 0.0159 & 0.0158 & 0.049 & -0.240 & 0.374 & -0.140 & -0.005 & 0.041 & 0.128 \\
\hline$N M O M$ & 0.0077 & 0.0096 & 0.054 & -0.349 & 0.290 & -0.136 & -0.018 & 0.037 & 0.135 \\
\hline$N-A$ & -0.0082 & -0.0080 & 0.048 & -0.247 & 0.199 & -0.126 & -0.034 & 0.019 & 0.128 \\
\hline$R M-R F$ & 0.0045 & 0.0080 & 0.047 & -0.231 & 0.161 & -0.118 & -0.023 & 0.036 & 0.111 \\
\hline$H M L$ & 0.0040 & 0.0038 & 0.030 & -0.128 & 0.138 & -0.085 & -0.013 & 0.018 & 0.082 \\
\hline$S M B$ & 0.0026 & 0.0007 & 0.032 & -0.167 & 0.222 & -0.067 & -0.016 & 0.022 & 0.084 \\
\hline$A M I L S$ & 0.0026 & 0.0010 & 0.040 & -0.121 & 0.204 & -0.099 & -0.021 & 0.024 & 0.132 \\
\hline \multicolumn{10}{|c|}{ Panel B: Pairwise Correlations } \\
\hline & $M O M$ & $X M O M$ & $A M O M$ & $N M O M$ & $N-A$ & $R M-R F$ & $H M L$ & $S M B$ & \\
\hline$X M O M$ & 0.97 & & & & & & & & \\
\hline$A M O M$ & 0.87 & 0.85 & & & & & & & \\
\hline NMOM & 0.89 & 0.87 & 0.58 & & & & & & \\
\hline$N-A$ & 0.11 & 0.11 & -0.37 & 0.54 & & & & & \\
\hline$R M-R F$ & -0.06 & -0.06 & -0.19 & 0.06 & 0.26 & & & & \\
\hline$H M L$ & -0.21 & -0.20 & 0.14 & -0.47 & -0.68 & -0.32 & & & \\
\hline$S M B$ & 0.06 & 0.06 & 0.08 & 0.03 & -0.05 & 0.31 & -0.24 & & \\
\hline$A M I L S$ & -0.17 & -0.16 & 0.02 & -0.30 & -0.36 & -0.08 & 0.16 & 0.68 & \\
\hline
\end{tabular}


Table 4.1, Panel B presents the correlations between the various strategies. $M O M$ has a correlation of 0.97 with $X M O M, 0.87$ with $A M O M$ and 0.89 with $N M O M{ }^{4}$ $A M O M$ has a correlation of 0.58 with $N M O M$ and -0.37 with $N-A$. By conditioning on the direction of arbitrage trades, there is clear separation on correlations with the value factor ("HML"). AMOM is positively correlated with $H M L(0.14)$ while $N M O M(-0.47), \operatorname{MOM}(-0.21)$, and $X M O M(-0.20)$ are negatively correlated with $H M L$. There are also differences in correlation with the illiquidity risk factor. $A M O M(0.02)$ is positively correlated with $A M I L S$ while $N M O M(-0.30), M O M(-$ $0.17)$, and $X M O M(-0.16)$ are negatively correlated with $A M I L S$. The difference strategy designed to capture the influences of mispricing, $N-A$, is negatively correlated with both $H M L(-0.68)$ and $A M I L S(-0.36)$.

\subsection{Conditional Momentum Strategy Performance}

If momentum profitability is the result of behavioral explanations, the average returns to the strategy that is expected to contain more mispricing should have higher average returns. Table 4.2 provides average returns and risk-adjusted returns of the (conditional) momentum strategies for the period 1969 to 2010 and indicated sub-periods. The sample starts at 1969 to allow a minimum of 24 months when computing risk-adjusted returns. Risk adjustment is based on the Fama and French (1993) 3-factor model using 60-month rolling regressions (requiring a minimum of 24 months). The average and risk-adjusted returns for $M O M, X M O M$, and $A M O M$ are positive and highly significant in the 1969 to 2010 period as well as each subperiod with respective average monthly returns of $1.12 \%(t$-statistic $=5.53), 1.49 \%$ $(t$-statistic $=5.88)$, and $1.60 \%(t$-statistic $=7.70)$ for the 1969 to 2010 period. The

\footnotetext{
${ }^{4}$ Correlations presented in Table 4.1 suggest that the results are not simply the result of compound sorting on past returns. Further, tests described later in Section 4 regarding long-term reversal and expected momentum profits confirm that the results are not the result of sorting on more extreme past returns. In untabulated results, I also drop momentum groups 1 and 30 and then repeat the analysis and generate similar results.
} 
magnitudes between the $A M O M$ and $X M O M$ are similar across the time periods with and without risk-adjustment. NMOM is positive and significant for the full sample with an average monthly return of $0.75 \%(t$-statistic $=2.97)$. The average monthly return of NMOM is not significant in the 1993 to 2010 sub-period, however the risk-adjusted return is significant in each period. The average and risk-adjusted returns of the difference strategy, $N-A$, are negative and significant in each period with average monthly returns of $-0.85 \%$ ( $t$-statistic=-3.82) over the 1969 to 2010 period. ${ }^{5}$ Contrary to the behavioral explanations, the strategy expected to contain relatively more mispricing has significantly lower returns.

Table 4.2 also reports the squared Sharpe ratios (multiplied by 100) (SSR) of each of the momentum strategies computed similar to Brennan, Chordia, and Subrahmanyam (1998). The $S S R$ for all momentum strategies is larger in the 1969 to 1992 sub-period than the 1993 to 2010 sub-period. The SSR for AMOM (10.34) is larger than that of $M O M$ (5.74), XMOM (6.39), and NMOM (1.92) suggesting a greater return per unit risk for this strategy over the sample period 1969 to 2010 as well as each of the sub-periods. Also of interest is that each of the conditional strategies has a higher $S S R$ than the excess market return $(R M R F, 0.77)$, value factor $(H M L, 1.70)$ and size factor $(S M B, 0.26)$ over the 1969 to 2010 period.

\subsection{Long-term Reversal}

This section explores the relationship between momentum, relative misvaluation, and long-term reversal. Jegadeesh and Titman (1993) demonstrate that average returns to momentum portfolios exhibit positive returns over the initial 12 months which

${ }^{5}$ Over the 1926-1995 period, Grundy and Martin (2001) find average monthly momentum strategy returns of $-5.85 \%(t$-statistic $=-4.93)$ in Januaries and $1.01 \%(t$-statistic $=4.44)$ in other months. In untabulated results, average monthly returns to the NMOM strategy (1967-2010) were $-4.02 \%$ $(t$-statistic $=-3.86)$ in Januaries and $1.11 \%(t$-statistic $=4.28)$ in other months. By contrast, average monthly returns to the AMOM strategy (1967-2010) were $-1.13 \%$ ( $t$-statistic=-1.20) in Januaries and $1.69 \%$ ( $t$-statistic $=7.82)$ in other months. 
Table 4.2

Conditional Momentum Strategy Performance (1969-2010)

This table presents average returns, risk-adjusted returns, and squared Sharpe ratios for (conditional) momentum (6/1/6) strategies formed on past returns and residual firm value (RFV) for the period 1969-2010. RFV value is estimated using cross-sectional valuation regressions detailed in Section 2.3. Panel A reports average and risk-adjusted returns for the momentum strategies. Construction of the (conditional) momentum strategies is detailed in Table 4.1. RMRF, HML, and $S M B$ are the Fama and French factors downloaded from Ken French's website. Portfolios are formed monthly and held for 6 months. One month is skipped between measurement period and calculation of holding period returns to minimize microstructure issues. Risk-adjustment is based on the Fama and French 3-factor model (FF3) using 60-month rolling regressions (require a minimum 24 months). T-statistics reported below coefficient estimates are based on Newey-West standard errors.

\begin{tabular}{|c|c|c|c|c|c|c|c|c|c|}
\hline & \multicolumn{3}{|c|}{ Average Returns } & \multicolumn{3}{|c|}{ Risk-Adj. Returns(FF3) } & \multicolumn{3}{|c|}{ Squared Sharpe Ratios (x100) } \\
\hline & $1969-2010$ & $1969-1992$ & $1993-2010$ & $1969-2010$ & 1969-1992 & $1993-2010$ & $1969-2010$ & 1969-1992 & $1993-2010$ \\
\hline \multicolumn{10}{|c|}{ Unconditional Momentum Strategies: } \\
\hline \multirow[t]{2}{*}{$M O M$} & 1.12 & 1.17 & 1.04 & 1.32 & 1.37 & 1.25 & \multirow[t]{2}{*}{5.74} & \multirow[t]{2}{*}{10.37} & \multirow[t]{2}{*}{3.28} \\
\hline & 5.53 & 5.68 & 2.78 & 7.29 & 7.55 & 3.67 & & & \\
\hline \multirow[t]{2}{*}{$X M O M$} & 1.49 & 1.62 & 1.30 & 1.75 & 1.88 & 1.58 & \multirow[t]{2}{*}{6.39} & \multirow[t]{2}{*}{13.39} & \multirow[t]{2}{*}{3.12} \\
\hline & 5.88 & 6.29 & 2.77 & 7.79 & 8.67 & 3.65 & & & \\
\hline \multicolumn{10}{|c|}{ Conditional Momentum Strategies: } \\
\hline \multirow[t]{2}{*}{$A M O M$} & 1.60 & 1.66 & 1.52 & 1.57 & 1.59 & 1.54 & \multirow[t]{2}{*}{10.34} & \multirow[t]{2}{*}{18.05} & \multirow[t]{2}{*}{6.17} \\
\hline & 7.70 & 7.67 & 3.97 & 8.59 & 8.60 & 4.44 & & & \\
\hline \multirow[t]{2}{*}{$N M O M$} & 0.75 & 0.87 & 0.59 & 1.15 & 1.26 & 0.99 & \multirow[t]{2}{*}{1.92} & \multirow[t]{2}{*}{3.87} & \multirow[t]{2}{*}{0.82} \\
\hline & 2.97 & 3.46 & 1.25 & 5.66 & 6.51 & 2.62 & & & \\
\hline \multirow[t]{2}{*}{$N-A$} & -0.85 & -0.78 & -0.93 & -0.42 & -0.33 & -0.55 & \multirow[t]{2}{*}{3.12} & \multirow[t]{2}{*}{3.66} & \multirow[t]{2}{*}{2.76} \\
\hline & -3.82 & -3.43 & -2.27 & -3.10 & -2.26 & -2.28 & & & \\
\hline \multicolumn{10}{|c|}{ Fama and French 3-factors: } \\
\hline \multirow[t]{2}{*}{$R M R F$} & 0.41 & 0.33 & 0.52 & & & & \multirow[t]{2}{*}{0.77} & \multirow[t]{2}{*}{0.48} & \multirow[t]{2}{*}{1.28} \\
\hline & 1.83 & 1.13 & 1.48 & & & & & & \\
\hline \multirow[t]{2}{*}{$H M L$} & 0.40 & 0.44 & 0.34 & & & & \multirow[t]{2}{*}{1.70} & \multirow[t]{2}{*}{2.68} & \multirow[t]{2}{*}{0.94} \\
\hline & 2.46 & 2.33 & 1.22 & & & & & & \\
\hline$S M B$ & 0.16 & 0.09 & 0.26 & & & & 0.26 & 0.10 & 0.51 \\
\hline & 1.11 & 0.47 & 1.23 & & & & & & \\
\hline
\end{tabular}


partially reverse over a two to three year horizon. ${ }^{6}$. Jegadeesh and Titman (2001) argue that long-term reversal is more consistent with mispricing and behavioral explanations rather than sorts on unconditional expected returns as argued by Conrad and Kaul (1998). I examine the long-term reversal of the (conditional) momentum strategies which is commonly associated with investor overreaction to show that that the conditional momentum strategies successfully separate firms according to their relative level of mispricing. If mispricing is responsible for long-term reversal, then the interaction of momentum traders and arbitrageurs suggests that the arbitrageimpeding strategy, $N M O M$, should demonstrate a greater level of long-term reversal than the arbitrage-reinforcing strategy, $A M O M$.

Table 4.3 presents average annual returns to stocks underlying the (conditional) momentum strategies for each of the 5 years following portfolio formation. Returns to each of the momentum strategies are positive in the initial year following portfolio formation (all except $N M O M$ are significant). $M O M$ and $X M O M$ both exhibit a return profile that is consistent with Jegadeesh and Titman's findings - returns are positive and significant in the first year with reversal in the second and third year following portfolio formation. Consistent with the argument that $A M O M$ contains less mispricing than $N M O M$, Table 4.3 shows that there is no reversal in the $A M O M$ strategy, but negative and significant reversal in $N M O M$ for each of the four years following the first year after portfolio formation. ${ }^{7}$ Further, the difference strategy, $N$-A, has negative and highly significant returns in each of the 5 years following portfolio formation.

\footnotetext{
${ }^{6}$ Jegadeesh and Titman (1993) find cumulative returns of approximately $9.5 \%$ in the first year that decline by the end of the third year to approximately $4 \%$. They argue that this provides evidence that momentum is not the result of sorting on expected returns. They note that the reversal in years 2 and 3 is not significant due to the precision of the estimates over their sample period. Jegadeesh and Titman (2001) demonstrate significant reversal in momentum portfolios in the second to fifth year following portfolio formation.

${ }^{7}$ In untabulated results, the $A M O M$ strategy has only 4 negative monthly returns (none significant at $10 \%$ level) during the 36 months following portfolio formation, while $N M O M$ is negative in 29 of the 36 months (significant in 21 at the $10 \%$ level).
} 
Table 4.3

Conditional Momentum Strategy Average Annual Post-Formation Returns (1969-2010)

This table presents average annual post-formation returns of the stocks underlying the (conditional) momentum strategies for each of the five years following portfolio formation for the period 19692010. Construction of the (conditional) momentum strategies is detailed in Table 4.1. UMOM represents returns to a relatively undervalued momentum strategy that is long undervalued past winners and short undervalued past losers. FMOM and $O M O M$ are relative momentum strategies formed using relatively fairly valued and overvalued securities, respectively. Annual returns are computed for the one to five years beginning with the initial holding period. One month is skipped between measurement period and calculation of initial holding period to minimize microstructure issues. Average returns are multiplied by 100. T-statistics reported below coefficient estimates are based on Newey-West standard errors.

\begin{tabular}{|c|c|c|c|c|c|c|c|c|c|c|c|c|c|c|c|}
\hline & & Year 1 & & & Year 2 & & & Year 3 & & & Year 4 & & & Year 5 & \\
\hline & Long & Short & L-S & Long & Short & L-S & Long & Short & L-S & Long & Short & L-S & Long & Short & L-S \\
\hline Unconditi & onal $\mathrm{M}$ & Ioment & um Stre & tegies: & & & & & & & & & & & \\
\hline$M O M$ & 15.51 & 7.20 & 8.30 & 12.58 & 16.53 & -3.95 & 13.86 & 16.74 & -2.88 & 16.98 & 16.56 & 0.42 & 16.65 & 17.48 & -0.83 \\
\hline & 4.89 & 2.38 & 3.83 & 4.23 & 5.08 & -2.16 & 4.83 & 4.85 & -1.58 & 4.87 & 4.78 & 0.25 & 4.93 & 6.36 & -0.39 \\
\hline$X M O M$ & 15.10 & 4.59 & 10.52 & 11.83 & 17.53 & -5.70 & 12.64 & 16.97 & -4.33 & 16.85 & 17.74 & -0.89 & 17.32 & 17.91 & -0.59 \\
\hline & 4.08 & 1.37 & 3.90 & 3.51 & 4.58 & -2.37 & 4.03 & 4.24 & -1.85 & 4.01 & 4.36 & -0.44 & 4.24 & 6.13 & -0.21 \\
\hline Condition & al Mom & nentum & n Strate & gies: & & & & & & & & & & & \\
\hline$A M O M$ & 18.63 & 3.86 & 14.77 & 16.48 & 13.34 & 3.14 & 17.08 & 14.71 & 2.37 & 19.78 & 14.24 & 5.53 & 18.42 & 16.11 & 2.31 \\
\hline & 5.77 & 1.31 & 6.51 & 5.40 & 4.44 & 1.66 & 5.71 & 4.32 & 1.09 & 5.36 & 4.28 & 2.60 & 4.82 & 5.92 & 0.81 \\
\hline NMOM & 12.95 & 9.62 & 3.33 & 9.29 & 19.79 & -10.50 & 11.42 & 18.22 & -6.79 & 14.01 & 19.59 & -5.58 & 14.34 & 18.71 & -4.37 \\
\hline & 3.82 & 2.97 & 1.27 & 3.13 & 5.20 & -4.23 & 3.82 & 5.03 & -3.35 & 4.07 & 4.98 & -2.80 & 4.39 & 6.38 & -1.93 \\
\hline$N-A$ & -5.67 & 5.76 & -11.44 & -7.19 & 6.45 & -13.64 & -5.66 & 3.51 & -9.16 & -5.77 & 5.35 & -11.12 & -4.08 & 2.60 & -6.68 \\
\hline & -3.99 & 4.84 & -5.23 & -6.28 & 3.60 & -5.61 & -4.25 & 2.93 & -4.21 & -5.84 & 3.40 & -5.23 & -2.32 & 2.20 & -3.02 \\
\hline Relative & Value M & Aoment & tum Str & tegies: & & & & & & & & & & & \\
\hline$U M O M$ & 18.63 & 9.62 & 9.01 & 16.48 & 19.79 & -3.31 & 17.08 & 18.22 & -1.13 & 19.78 & 19.59 & 0.18 & 18.42 & 18.71 & -0.29 \\
\hline & 5.77 & 2.97 & 4.02 & 5.40 & 5.20 & -1.48 & 5.71 & 5.03 & -0.59 & 5.36 & 4.98 & 0.09 & 4.82 & 6.38 & -0.09 \\
\hline$F M O M$ & 14.71 & 8.27 & 6.44 & 12.76 & 16.63 & -3.87 & 13.07 & 17.24 & -4.17 & 17.66 & 16.07 & 1.59 & 17.24 & 17.25 & -0.01 \\
\hline & 4.97 & 2.79 & 3.00 & 4.24 & 5.25 & -1.98 & 4.70 & 5.05 & -2.09 & 5.15 & 4.84 & 0.88 & 5.28 & 6.42 & -0.01 \\
\hline$O M O M$ & 12.95 & 3.86 & 9.10 & 9.29 & 13.34 & -4.05 & 11.42 & 14.71 & -3.28 & 14.01 & 14.24 & -0.23 & 14.34 & 16.11 & -1.77 \\
\hline & 3.82 & 1.31 & 3.81 & 3.13 & 4.44 & -2.23 & 3.82 & 4.32 & -1.73 & 4.07 & 4.28 & -0.14 & 4.39 & 5.92 & -0.95 \\
\hline$U-O$ & 5.67 & 5.76 & -0.09 & 7.19 & 6.45 & 0.74 & 5.66 & 3.51 & 2.15 & 5.77 & 5.35 & 0.42 & 4.08 & 2.60 & 1.48 \\
\hline & 3.99 & 4.84 & -0.06 & 6.28 & 3.60 & 0.42 & 4.25 & 2.93 & 1.66 & 5.84 & 3.40 & 0.27 & 2.32 & 2.20 & 0.73 \\
\hline
\end{tabular}


This evidence suggests that the interaction of momentum traders and arbitrageurs significantly impacts the level of mispricing and profitability of the momentum strategy. When momentum and arbitrage trades are aligned as in the $A M O M$ strategy, prices converge and there is relatively less mispricing. When momentum and arbitrage trades are not aligned, demand pressure from momentum traders may push prices further away from fundamental value and may lead arbitrageurs to reduce their arbitrage intensity. No long-term reversal (e.g. long-term positive returns) in the $A M O M$ strategy is consistent with Conrad and Kaul's (1998) suggestion that sorting on past returns results in effectively sorting firms according to unconditional expected returns. The long-term reversal of returns to the NMOM strategy is consistent with Jegadeesh and Titman's (2001) argument that long-term reversal is evidence of mispricing and behavioral explanations of momentum.

Together, the long-term reversal tests combined with the average returns of the conditional strategies cast doubt on the ability of behavioral explanations to explain average momentum profitability. The subset of momentum stocks that appear to contain relatively more mispricing also have significantly lower returns.

One possible argument against this inference is that the evidence regarding longterm reversal only rules out mispricing from the perspective of investor overreaction, but not investor underreaction. It could be that the higher average returns in $A M O M$ are the result of investor underreaction to news in prior periods. Behavioral models of Barberis, Shleifer, and Vishny (1998) and Hong and Stein (1999) suggest that momentum profitability may result from a combination of investor overreaction and underreaction to value-relevant information. If momentum profitability is the result of investor underreaction, this suggests that all market participants, including arbitrageurs, systematically underreact to observable, value-relevant information. However, the limits-to-arbitrage literature (and the model in Appendix A) suggests that arbitrageurs will increase their arbitrage intensity when momentum trades are expected to reinforce the arbitrage process (as compared to the case of 
no momentum trades). Thus, there should be little mispricing in momentum stocks when arbitrageurs are able to observe past returns and infer that momentum trades will expedite the correction of mispricing. If arbitrageurs supply sufficient capital to eliminate mispricing due to investor underreaction, then momentum profits should be largely due to cross-sectional differences in expected returns.

\subsection{Expected Momentum Profits}

This section analyzes the differences in risk exposure of the conditional momentum strategies. While relative misvaluation can be caused by both mispricing and omitted risk factors, the evidence presented thus far suggests that $N M O M$ contains more mispricing than $A M O M$. Since $A M O M$ has significantly higher average returns (Table 4.2) and contains less mispricing (Table 4.3) than NMOM, finance theory suggests that $A M O M$ should have higher exposure to priced risk factors. Alternatively, if momentum profits are the result of mispricing, such as investor underreaction, there should be little correlation between $A M O M$ and priced risk factors.

To estimate the influence of risk on each of the conditional momentum strategies, I compute expected momentum profits for each (conditional) momentum strategy following the approach of Liu and Zhang (2008). Table 4.4 estimates the proportion of momentum strategy profits explained by two risk models that include risk factors correlated with time-varying expected returns. Model 1 is the Fama and French (1993) 3-factor model (FF3) augmented with change in industrial production (MP) (i.e. Liu and Zhang (2008)) and Model 2 is the Chen, Roll and Ross (1986) five-factor macroeconomic risk model (CRR) which includes change in industrial production $(M P)$, unexpected inflation $(U I)$, change in expected inflation $(D E I)$, term spread 
$(U T S)$, and default spread (UPR). The variables in the CRR model are constructed as in Liu and Zhang (2008). ${ }^{8}$

Table 4.4, Panel A presents full-sample estimates of risk premia computed using FMB regressions for each of the three models. Test assets (30 portfolios) include 10 Size portfolios, 10 B/M portfolios, and 10 Momentum portfolios downloaded from Ken French's website. ${ }^{9}$ In the first stage, time-series coefficients are estimated by regressing the excess returns to the test assets on the risk factors in the indicated model over the full sample period. In the second stage, I perform monthly crosssectional regressions of the excess returns to the test assets on the coefficient estimates obtained in the first stage regressions. The risk premia estimates $\left(E\left[\gamma_{j}\right]\right)$ are the time series averages of the cross-sectional coefficient estimates obtained in the second-stage regression. In Model 1, the estimated risk premium is significant for $H M L(0.61$, $t$-statistic $=2.73)$ and $M P(1.08, t$-statistic $=4.00)$. In Model 2 , the risk premium is significant for change in industrial production $(M P, 1.43, t$-statistic $=2.41)$. Reported t-statistics are corrected for the error-in-variables problem following Shanken (1992).

Table 4.4, Panel B presents full-sample time-series coefficient estimates obtained by regressing each of the momentum strategies on the respective risk models. In the interest of space, I will limit my discussion to the Fama and French (1993) 3factor model augmented with change in industrial production measure $(M P)$. The loadings on $R M R F$ are negative for both $A M O M(-0.23, t$-statistic=-3.02) and NMOM (-0.10, t-statistic=-1.36). The NMOM strategy has a negative and highly significant loading on $H M L(-0.94, t$-statistic=-6.06), while $A M O M$ has a positive and insignificant loading $(0.17, t$-statistic $=0.86)$. Both strategies have small and

\footnotetext{
${ }^{8}$ Similar results are achieved using the Fama and French (1993) 3-factor model (FF3) which includes excess market return $(R M R F)$, the value factor $(H M L)$, and the size factor $(S M B)$.

${ }^{9}$ Lewellen, Nagel, and Shanken (2010) argue that the strong factor structure of the 25 size-B/M portfolios commonly used in the academic literature can generate misleading results in asset pricing tests. One of the suggestions to reduce the problem is to expand the set of test assets to reduce the tight factor structure of the size-B/M portfolios. By following Liu and Zhang (2008), I minimize this issue by including momentum portfolios as well as portfolios sorted independently on size and portfolios independently sorted on $\mathrm{B} / \mathrm{M}$.
} 
Table 4.4

Expected Momentum Profits (1967-2010)

This table presents expected momentum profits to conditional momentum strategies for the period 1967 to 2010 for two model specifications. Model 1 includes the Fama and French 3-factor model (excess market return- $R M R F$, value$H M L$, and size- $S M B)$ as well as $M P$. Model 2 includes macroeconomic risk variables (MP, UI, DEI, UTS, and $U P R)$. Conditional momentum strategies are defined in Table 4.1. Six-month holding period returns are calculated for each portfolio. One month is skipped between measurement period and calculation of holding period returns to minimize microstructure issues. Panel A reports risk premia estimates from a two-stage Fama-MacBeth regression using 10 size, 10 book-to-market, and 10 momentum portfolios (from Ken French's website) as test assets. T-statistics below risk premia estimates are computed using standard errors corrected following Shanken (1992). Panel B reports full-sample coefficients estimated by regressing each of the conditional momentum strategies on the risk factors in the indicated model. Panel $\mathrm{C}$ reports the expected momentum profits $(E[* M O M])$ computed by multiplying the appropriate risk exposure times the estimates price of risk, the expected momentum profits scaled by realized average momentum profits $(\%-* M O M=E[* M O M] / * M O M)$, and the $p$-value from a test of the difference in expected returns between $A M O M(E[A M O M])$ and each of the other strategies $(E[* M O M])$. T-statistics reported below coefficient estimates are based on Newey-West standard errors.

\begin{tabular}{|c|c|c|c|c|c|c|c|c|c|c|c|c|}
\hline & Model 1 & : FF3 + & $\Delta$ Ind. $\mathrm{P}$ & rod. & & & Model 2: & Chen, $\mathrm{Rc}$ & oll, and $\mathrm{R}$ & Ross $(1986)$ & & \\
\hline Panel A: Es & $\begin{array}{c}\text { timated } \\
\text { INT }\end{array}$ & $\begin{array}{c}\text { Risk Prer } \\
\text { RMRF }\end{array}$ & $\begin{array}{c}\operatorname{nia}\left(\gamma_{j} \text { e }\right. \\
H M L \\
\end{array}$ & $\begin{array}{c}\text { stimates, } \\
S M B\end{array}$ & $\begin{array}{c}\text { 2-stage } \\
M P\end{array}$ & $F M B$ using 10 & $\begin{array}{l}0 \text { MOM } \\
I N T \\
\end{array}$ & $\begin{array}{c}10 \mathrm{BM}, \\
\mathrm{MP}\end{array}$ & $\begin{array}{c}\text { and } 10 \mathrm{~S} \\
U I\end{array}$ & $\begin{array}{c}Z \text { portfoli } \\
D E I\end{array}$ & $\begin{array}{l}\text { ios): } \\
\text { UTS }\end{array}$ & $U P R$ \\
\hline$E\left[\gamma_{j}\right]$ & $\begin{array}{l}0.42 \\
0.64\end{array}$ & $\begin{array}{l}0.31 \\
0.48\end{array}$ & $\begin{array}{l}0.61 \\
2.73\end{array}$ & $\begin{array}{l}-0.14 \\
-0.62\end{array}$ & $\begin{array}{l}1.08 \\
4.01\end{array}$ & $E\left[\gamma_{j}\right]$ & $\begin{array}{l}0.25 \\
0.48\end{array}$ & $\begin{array}{l}1.43 \\
2.41\end{array}$ & $\begin{array}{l}-0.10 \\
-0.70\end{array}$ & $\begin{array}{l}-0.04 \\
-0.53\end{array}$ & $\begin{array}{l}0.90 \\
1.30\end{array}$ & $\begin{array}{l}-0.42 \\
-1.61\end{array}$ \\
\hline Panel B: Ti & $\begin{array}{l}\text { me Serie } \\
M O M\end{array}$ & $\begin{array}{l}\text { es Risk ( } \\
X M O M\end{array}$ & $\begin{array}{l}\text { ull-sampl } \\
\text { AMOM }\end{array}$ & $\begin{array}{l}\beta_{j} \text { estin } \\
\text { JMOM }\end{array}$ & $\begin{array}{c}\text { nates) : } \\
\quad N-A\end{array}$ & & $M O M$ & $X M O M$ & $A M O M$ & NMOM & $N-A$ & \\
\hline$R M R F$ & -0.16 & -0.20 & -0.23 & -0.10 & 0.13 & $M P$ & 0.44 & 0.67 & 0.71 & & $\begin{array}{l}-0.38 \\
-1.30\end{array}$ & \\
\hline$H M L$ & $\begin{array}{l}-2.20 \\
-0.38 \\
-219\end{array}$ & $\begin{array}{l}-2.26 \\
-0.48 \\
-2.26\end{array}$ & $\begin{array}{r}-3.02 \\
0.17 \\
0.86\end{array}$ & $\begin{array}{l}-1.36 \\
-0.94 \\
-6.06\end{array}$ & $\begin{array}{l}2.98 \\
-1.11 \\
-14.27\end{array}$ & $U I$ & $\begin{array}{r}1.75 \\
-0.54\end{array}$ & $\begin{array}{r}2.25 \\
-0.11\end{array}$ & $\begin{array}{l}2.41 \\
0.02\end{array}$ & $\begin{array}{r}1.10 \\
-1.07 \\
0.88\end{array}$ & $\begin{array}{l}-1.30 \\
-1.09\end{array}$ & \\
\hline$S M B$ & $\begin{array}{l}-2.19 \\
0.07\end{array}$ & $\begin{array}{c}-2.26 \\
0.09\end{array}$ & $\begin{array}{l}0.86 \\
0.27\end{array}$ & $\begin{array}{l}-6.06 \\
-0.12\end{array}$ & $\begin{array}{l}-14.27 \\
-0.38\end{array}$ & $D E I$ & $\begin{array}{c}-0.49 \\
4.41\end{array}$ & $\begin{array}{c}-0.08 \\
4.21\end{array}$ & $\begin{array}{l}0.01 \\
3.23\end{array}$ & $\begin{array}{l}-0.88 \\
5.49\end{array}$ & $\begin{array}{l}-0.93 \\
2.26 \\
0.70\end{array}$ & \\
\hline$M P$ & $\begin{array}{l}0.39 \\
0.73 \\
2.53\end{array}$ & $\begin{array}{l}0.42 \\
0.98 \\
2.71\end{array}$ & $\begin{array}{l}1.29 \\
0.93 \\
3.08\end{array}$ & $\begin{array}{c}-0.73 \\
0.66 \\
2.27\end{array}$ & $\begin{array}{l}-4.95 \\
-0.26 \\
-1.71\end{array}$ & $\begin{array}{l}U T S \\
U P R\end{array}$ & $\begin{array}{l}1.79 \\
-0.28 \\
-1.94 \\
-0.89 \\
-1.31\end{array}$ & $\begin{array}{c}1.32 \\
-0.42 \\
-2.17 \\
-0.88 \\
-1.00\end{array}$ & $\begin{array}{l}1.02 \\
-0.23 \\
-1.50 \\
-0.94 \\
-1.28\end{array}$ & $\begin{array}{c}2.01 \\
-0.44 \\
-2.25 \\
-0.76 \\
-1.00\end{array}$ & $\begin{array}{c}0.70 \\
-0.21 \\
-1.13 \\
0.18 \\
0.31\end{array}$ & \\
\hline Panel C: Ex & $\begin{array}{l}\text { pected } M \\
\text { MOM }\end{array}$ & $\begin{array}{l}\text { Momentum } \\
X M O M\end{array}$ & $\begin{array}{l}\text { 2 Profits } \\
\text { AMOM }\end{array}$ & $\begin{array}{l}E[* M O I \\
N M O M\end{array}$ & $\begin{array}{c}M]=\sum \\
N-A\end{array}$ & $\left.=1 \hat{\beta}_{j} * \hat{\gamma}_{j}\right):$ & $M O M$ & $X M O M$ & $A M O M$ & NMOM & $N-A$ & \\
\hline $\begin{array}{l}R M R F \\
H M L \\
S M B \\
M P\end{array}$ & $\begin{array}{c}-0.05 \\
-0.23 \\
-0.01 \\
0.79\end{array}$ & $\begin{array}{c}-0.06 \\
-0.29 \\
-0.01 \\
1.07\end{array}$ & $\begin{array}{c}-0.07 \\
0.10 \\
-0.04 \\
1.01\end{array}$ & $\begin{array}{c}-0.03 \\
-0.57 \\
0.02 \\
0.72\end{array}$ & $\begin{array}{c}0.04 \\
-0.68 \\
0.06 \\
-0.29\end{array}$ & $\begin{array}{c}M P \\
U I \\
D E I \\
U T S \\
U P R\end{array}$ & $\begin{array}{c}0.55 \\
0.34 \\
-0.48 \\
-0.15 \\
0.40 \\
\end{array}$ & $\begin{array}{c}0.82 \\
0.36 \\
-0.55 \\
-0.25 \\
0.42\end{array}$ & $\begin{array}{c}0.92 \\
0.18 \\
-0.33 \\
-0.11 \\
0.41\end{array}$ & $\begin{array}{c}0.40 \\
0.47 \\
-0.59 \\
-0.27 \\
0.30 \\
\end{array}$ & $\begin{array}{c}-0.52 \\
0.29 \\
-0.26 \\
-0.16 \\
-0.11 \\
\end{array}$ & \\
\hline $\begin{array}{l}E[* M O M] \\
\%-* M O M\end{array}$ & $\begin{array}{c}0.50 \\
44.3 \%\end{array}$ & $\begin{array}{c}0.70 \\
45.5 \%\end{array}$ & $\begin{array}{c}1.00 \\
62.7 \%\end{array}$ & $\begin{array}{c}0.13 \\
16.8 \%\end{array}$ & $\begin{array}{c}-0.87 \\
105.7 \%\end{array}$ & $\begin{array}{c}E[* M O M] \\
\%-* M O M\end{array}$ & $\begin{array}{c}0.62 \\
54.7 \%\end{array}$ & $\begin{array}{c}0.79 \\
51.7 \%\end{array}$ & $\begin{array}{c}1.07 \\
66.9 \%\end{array}$ & $\begin{array}{c}0.27 \\
35.3 \%\end{array}$ & $\begin{array}{c}-0.79 \\
96.5 \%\end{array}$ & \\
\hline $\begin{array}{l}\text { Test } E[A M C \\
p \text {-value }\end{array}$ & $\begin{array}{c}M]-E \\
0.00\end{array}$ & $\begin{array}{c}{[* M O M]} \\
0.02\end{array}$ & & 0.00 & 0.00 & & 0.00 & 0.00 & & 0.00 & 0.00 & \\
\hline
\end{tabular}


insignificant loadings on $S M B$. Both $A M O M(0.93, t$-statistic=3.08) and $N M O M$ $(0.66, t$-statistic $=2.27)$ have positive and significant loadings on $M P$. The positive and significant loadings on $M P$ are consistent with (at least a portion of) momentum profits being related to changes in expected returns that vary with the business cycle.

Table 4.4, Panel C computes expected momentum profits $(E[* M O M])^{10}$ by summing up the product of the factor loadings estimated in Panel B and the risk premia estimated in Panel A. For each of the models, the expected momentum profits of the $A M O M$ strategy are larger in magnitude than the other strategies with monthly expected return estimates of $1.00 \%$ in Model 1 and 1.07\% in Model 2. For comparison, the expected monthly return estimates for the $N M O M$ strategy are $0.13 \%$ in Model 1 and $0.27 \%$ in Model 2. Thus, the expected strategy return due to risk exposure for $A M O M$ is 3 to 6 times larger than $N M O M$. The magnitude of the expected return to $A M O M$ is $30 \%$ to $100 \%$ larger than the expected returns to $M O M$ and $X M O M$

I also compute the percentage of strategy returns explained by expected risk premia $(\%-* M O M)$ as $E[* M O M]$ divided by average strategy returns. AMOM has a higher \%-*MOM than any of the other strategies. For example, in Model 2, the percentage of strategy returns explained by expected momentum profits for the $A M O M, N M O M, M O M$, and $X M O M$ strategies are respectively $66.9 \%, 35.3 \%$, $54.7 \%$, and 51.7\%. For Model 1 the respective percentages are 62.7\%, 16.8\%, 45.5\%, and $44.3 \%$. These results suggest that the profitability of the momentum strategy is significantly related to compensation for factor risk exposure. Reported $p$-values at the bottom of panel $\mathrm{C}$ show that $E[A M O M]$ is significantly larger than the expected momentum profits of $M O M, X M O M$, and $N M O M$ in both models with $p$-values ranging from 0.00 to 0.05 .

Together, these results suggest that stocks where momentum trades reinforce arbitrage trades have higher average returns that contain less mispricing and are

\footnotetext{
$\overline{10}$ The notation "* MOM" represents the (conditional) momentum strategy indicated by the column heading.
} 
largely explained by exposure to priced risk factors. The ability of a standard set of risk factors to explain more than two-thirds of the realized momentum profits cast doubts on the ability of investor underreaction to explain average momentum profitability.

\subsection{Expected Growth Rates}

Conrad and Kaul (1998) suggest that sorting firms on past returns is consistent with sorting firms on unconditional expected returns. Empirical results in prior sections show that $A M O M$ has significantly higher average returns than $N M O M$. Results related to long-term reversal provide evidence that conditioning on the direction of arbitrage trades effectively sorts firms such that $N M O M$ contains more mispricing than $A M O M$. Results related to expected momentum profits suggest that the profitability of the $A M O M$ strategy is largely explained by risk compensation. If the profitability of the momentum strategy is largely explained by cross-sectional differences in risk between winners and losers then there should be some cross-sectional differences in proxies for expected returns (e.g. future growth rates).

Table 4.5 reports event-time averages of six firm-level measures for the long and short portfolios of the $A M O M$ and $N M O M$ strategies. For each of the firm-level measures, an equal-weighted average of the measure is computed for each of the indicated portfolios at the indicated points in time. Current represents the average firm measures at initial portfolio formation computed based on information known at time t. The 1 yr column reports the average firm measures based on information known 12 months after portfolio formation. The $2 \mathrm{yr}$ to $5 \mathrm{yr}$ columns report the average firm measures computed at the indicated period following portfolio formation.

$\underline{R F V}$. Current period values of $R F V$ show that firms in the $A M O M$-Long (Short) and $N M O M$-Short (Long) portfolio are relatively undervalued (overvalued) on average. The misvaluation persists beyond the current period, but converges towards zero over the subsequent 5 years. This is consistent with the correction of mis- 
Table 4.5

Conditional Momentum Strategies and Firm Operating Performance (1967-2010)

This table presents average operating performance statistics for the long and short legs of the conditional momentum strategies for the period 1967 to 2010. Construction of the (conditional) momentum strategies is detailed in Table 4.1. Current represents the time series average of the operating statistics measured at the beginning of the initial holding period. Time series averages of the operating statistics are also reported in 1 year increments for up to 5 years following portfolio formation $(1 \mathrm{yr} . .5 \mathrm{yr})$. All firms are included in the periods for which they have valid measures. $R F V$ is computed as described in Section II, Price-to-Earnings ratio is computed as market equity scaled by net income. Asset Growth is the one year percentage change in total assets. Sales Growth is the one year percentage change in total sales. Cashflow is computed as net income plus depreciation plus deferred taxes. Cashflow Margin is current year cashflow divided by current year sales. Cashflow ROE is computed as Cashflow divided by prior period book equity.

\begin{tabular}{|c|c|c|c|c|c|c|c|c|c|c|c|c|}
\hline Portfolio & Current & $1 \mathrm{yr}$ & $2 \mathrm{yr}$ & $3 \mathrm{yr}$ & $4 \mathrm{yr}$ & $5 \mathrm{yr}$ & Current & $1 \mathrm{yr}$ & $2 \mathrm{yr}$ & $3 \mathrm{yr}$ & $4 \mathrm{yr}$ & $5 \mathrm{yr}$ \\
\hline & \multicolumn{6}{|c|}{$R F V$} & \multicolumn{6}{|c|}{ Price-to-Earnings Ratio } \\
\hline$A M O M$-Long & -0.35 & -0.17 & -0.22 & -0.21 & -0.19 & -0.19 & 10.1 & 15.5 & 15.0 & 16.1 & 14.9 & 15.2 \\
\hline$N M O M$-Long & 1.04 & 0.69 & 0.42 & 0.33 & 0.29 & 0.27 & 43.1 & 32.2 & 25.8 & 22.2 & 22.4 & 21.1 \\
\hline$A M O M$-Short & 0.46 & 0.18 & 0.20 & 0.20 & 0.18 & 0.16 & 23.6 & 17.5 & 17.8 & 18.9 & 19.2 & 19.3 \\
\hline \multirow[t]{2}{*}{$N M O M$-Short } & -0.89 & -0.55 & -0.36 & -0.32 & -0.29 & -0.27 & 6.4 & 10.8 & 11.4 & 14.0 & 13.5 & 14.4 \\
\hline & \multicolumn{6}{|c|}{ Asset Growth (1-year) } & \multicolumn{6}{|c|}{ Sales Growth (1-year) } \\
\hline$A M O M$-Long & 0.11 & 0.10 & 0.16 & 0.16 & 0.15 & 0.14 & 0.12 & 0.12 & 0.17 & 0.16 & 0.14 & 0.13 \\
\hline$N M O M$-Long & 0.22 & 0.34 & 0.38 & 0.28 & 0.22 & 0.19 & 0.23 & 0.33 & 0.34 & 0.24 & 0.19 & 0.17 \\
\hline$A M O M$-Short & 0.30 & 0.31 & 0.16 & 0.13 & 0.14 & 0.14 & 0.28 & 0.27 & 0.15 & 0.14 & 0.15 & 0.14 \\
\hline \multirow[t]{2}{*}{$N M O M$-Short } & 0.21 & 0.10 & 0.04 & 0.05 & 0.08 & 0.10 & 0.19 & 0.08 & 0.04 & 0.08 & 0.10 & 0.11 \\
\hline & \multicolumn{6}{|c|}{ Cashflow Margin (CF/Sales) } & \multicolumn{6}{|c|}{ Cashflow ROE (CF/Lagged Book Equity) } \\
\hline$A M O M$-Long & 0.08 & 0.10 & 0.12 & 0.12 & 0.12 & 0.13 & 0.23 & 0.24 & 0.30 & 0.29 & 0.29 & 0.29 \\
\hline$N M O M$-Long & 0.07 & 0.11 & 0.12 & 0.12 & 0.12 & 0.12 & 0.26 & 0.37 & 0.39 & 0.34 & 0.31 & 0.29 \\
\hline$A M O M$-Short & 0.08 & 0.11 & 0.10 & 0.10 & 0.11 & 0.12 & 0.27 & 0.31 & 0.25 & 0.25 & 0.26 & 0.27 \\
\hline NMOM-Short & 0.10 & 0.07 & 0.06 & 0.07 & 0.09 & 0.10 & 0.28 & 0.19 & 0.16 & 0.20 & 0.23 & 0.25 \\
\hline
\end{tabular}


pricing or the systematic convergence of stock prices to industry-average valuations. Supporting the hypothesized interaction of arbitrageurs and momentum traders, the apparent correction is larger in the portfolios designed to contain a relatively higher level of mispricing ( NMOM portfolios).

Price - to - Earnings $(P / E)$. Current values of average $P / E$ ratios show that firms in the $A M O M$-Long (Short) and $N M O M$-Short (Long) portfolios have relatively low (high) $P / E$ ratios. The relatively lower (higher) market price per dollar in earnings persists after the Current period, but converges towards the mean (relatively high (low) $P / E$ ratios decrease (increase)) over the subsequent five years. The larger average correction in $P / E$ ratios for firms in the portfolios that appear to contain relatively more mispricing $(N M O M)$ is also consistent with investor overreaction.

If the profitability of the momentum strategy is largely explained by cross-sectional differences in risk between winners and losers then there should be some crosssectional differences in proxies for expected returns between winners and losers. To test this, I compute one-year measures of asset growth and sales growth at portfolio formation and for each of the subsequent five years (as proxies for expected growth rates).

Asset Growth (1-yr). Cooper, Gulen, and Schill (2008, CGS) find a negative relationship between future returns and one-year asset growth which they attribute to behavioral explanations. Specifically, they argue that "investors over extrapolate past gains to growth." If the findings of CGS are primarily the result of behavioral explanations, I may find evidence of differences between the AMOM and NMOM strategies.

Average asset growth in the $A M O M$-Long strategy starts at $11 \%$ and ranges from 10 to $16 \%$ over the subsequent periods. The AMOM-Short portfolio demonstrates declining asset growth rates moving from $30 \%$ in the current period to $14 \%$ in the fifth year following portfolio formation. The relatively stable but increasing (decreasing) asset growth rates in the $A M O M$-Long (Short) portfolio combined with 
movements of $P / E$ ratios in the same direction suggests that cross-sectional differences in expected returns is a plausible explanation for momentum profits in the AMOM strategy.

The average asset growth rate for firms in the $N M O M$-Long portfolio starts at $22 \%$, increases to $38 \%$, and then falls back to $19 \%$. For $N M O M$, the relatively higher growth rates, higher price-to-earnings ratios, and NMOM's underperformance relative to $A M O M$ are consistent with CGS's suggestion that the negative relationship between asset growth and future returns is due to investor overextrapolation of growth opportunities.

Sales Growth (1-yr). Lakonishok, Shleifer, and Vishny (1994, LSV) suggest that the underperformance of growth stocks may be due to investors overestimating future growth rates of growth stocks. If the overestimation of future growth rates results in mispricing, firms in the $A M O M$ and $N M O M$ strategies may have differences in variables that reflect firm growth such as sales growth. Similar to asset growth, I look at one-year change in sales and find a similar pattern.

The $A M O M$-Long portfolio demonstrates relatively stable average sales growth rates starting at $12 \%$ and reaching as high as $17 \%$ in the 2 nd year and then falling back to $13 \%$ in the fifth year. The $A M O M$-Short portfolio demonstrates a steady reduction in sales growth rates decreasing from $28 \%$ in the current period to $14 \%$ in the fifth year following portfolio formation. Similar to the findings with respect to future asset growth rates, this is consistent with cross-sectional differences in expected returns.

In contrast, $N M O M$-Long starts at $23 \%$, increases to $34 \%$ and then falls back to $17 \%$. The results are very similar to the asset growth category. The moderate increase in $A M O M$-Long sales growth rates over the subsequent 5 years is less likely to result in investor overreaction than the substantial increases in sales growth rates achieved by stocks in the $N M O M$-Long portfolio. The relatively higher sales growth rates in $N M O M$ combined with the substantially higher price-to-earnings ratios are 
consistent with LSV's suggestion that investors overreact to past growth rate signals such as sales growth when estimating future growth rates.

Profitability. The results related to asset growth and sales growth provide convincing evidence that the returns to the $A M O M$ and $N M O M$ portfolios are at least partially due to cross-sectional differences in expected firm growth rates. Large changes in $P / E$ ratios for $N M O M$ portfolio relative to $A M O M$ portfolio provides additional evidence that $N M O M$ contains more mispricing than $A M O M$. Further, the mispricing is consistent with investor overreaction to imprecise signals of firm growth rates. If there are cross-sectional differences in the profitability generated by the investing and sales activities, this apparent overreaction may be justified.

To confirm that there are not systematic differences in profitability, I compute the sales margin (cashflow/sales) and return on equity ("ROE", cashflow/lagged book equity). The results indicate that the average sales margin is similar between the $A M O M$-Long and $N M O M$-Long portfolios, so the apparent overreaction to Sales Growth is not likely the result of cross-sectional differences in sales margin. Similarly, cross-sectional differences in the ROE may partially explain the apparent overreaction to signals of firm growth. $A M O M$-Long portfolio has an initial average book ROE of $23 \%$ while the NMOM-Long starts at $26 \%$. At the end of 5 years, both portfolios have an ROE of $29 \%$. AMOM had relatively stable ROE across the 5 years while NMOM increased to as high as $39 \%$ before dropping back to $29 \%$. The volatility of the ROE, similar to the volatility of asset and sales growth rates, combined with the large differences in price-to-earnings ratios suggests that investor overextrapolation of future growth rates was larger in the portfolio where momentum trades impede arbitrage.

Overall, these finding are consistent with the previous results which suggest that momentum returns are largely explained by cross-sectional differences in expected returns. For both $A M O M$ and $N M O M$, winners have increasing future asset and sales growth rates while losers have decreasing growth rates. Interestingly, growth 
rates for the $N M O M$ winners portfolio are higher (and more volatile) than growth rates for the $A M O M$ winners portfolio. The $N M O M$ strategies also have a relatively larger average correction in $P / E$ ratios over the 5 years following portfolio formation. The larger $P / E$ corrections and more volatile growth rates suggest that at least a portion of the mispricing in $N M O M$ may be due to investor overreaction to past growth rates (e.g. Lakonishok, Shleifer and Vishny (1994) and Cooper, Gulen, and Schill (2008)). This correction in mispricing appears to mask the underlying crosssectional differences in future sales and asset growth rates between winners and losers in the NMOM portfolio which may help to partially explain the relatively low level of expected momentum profits for the $N M O M$ strategy in Table 4.4.

\subsection{Short-Sale Constraints and Overvaluation}

The analyses in the preceding sections suggest that momentum trades impede the arbitrage process. In this section I take a deeper look at the apparent investor overreaction (e.g. long-term reversal) of stocks in the arbitrage-impeding strategy. Specifically, I consider the interaction of arbitrageurs and momentum traders in the context of proxies for short-sale constraints and divergence of opinion. Miller (1977) develops a model where divergence of opinion in the presence of short-sale constraints can result in optimistic investors holding stocks at overvalued prices (i.e. above the equilibrium prices without short-sale constraints). This may result in the apparent investor overreaction observed in the arbitrage impeding strategy.

I start with a word of caution on this analysis. Divergence of opinion and shortsale constraints are not completely exogenous with respect to the interaction of arbitrageurs and momentum traders proposed in this paper. When momentum traders purchase overvalued winners, their demand pushes prices upwards away from funda-

mental value. As a result, I expect to find a relatively higher divergence of opinion by the nature of their trading in the opposite direction of arbitrage trades. Similar to noise trader risk, momentum traders purchasing overvalued winners can act as a 
short-sale constraint on arbitrageurs which leads to a reduction in arbitrage intensity allowing mispricing to persist or deepen. In Table 4.6, Panel A, I start by computing the time-series average $R F V$ for each portfolio to demonstrate that there appears to be a greater level of misvaluation in the overvalued winners and undervalued losers portfolios.

In Table 4.6, Panel B, I examine whether the apparent mispricing is due to non-momentum related short-sale constraints on stocks in the overvalued stocks. If short-sale constraints are binding, arbitrageurs would be unable to eliminate the mispricing because they cannot short the stock because it is not available to be borrowed. This differs from the proposed interaction of momentum traders and arbitrageurs where arbitrageurs choose not to short the stock in anticipation of momentum trades causing mispricing to deepen. Berkman, Dimitrov, Jain, Koch, and Tice (2009) use institutional ownership as a proxy for short sale constraints. The idea is that institutional traders are the primary source of lending, so stocks with low institutional ownership are considered as having binding short-sale constraints. Contrary to this explanation, I find that overvalued stocks have significantly higher average institutional ownership than undervalued stocks. The difference between overvalued winners and losers is not significant. This suggests that short-selling constraints are not binding on average for the stocks that become most overvalued.

In Table 4.6, Panels $\mathrm{C}$ and $\mathrm{D}$, I examine whether the apparent mispricing is due to divergence of opinion between investors. For dispersion of opinion, I use two measures motivated in Boehme, Danielsen, and Sorescu (2006, BDS), Turnover (Panel C) and Idiosyncratic Volatility (Panel D). Unlike measures based on analyst estimates, these measures have the benefit of being available for most stocks in CRSP. BDS test the Miller (1997) hypothesis that short sale constraints combined with divergence of opinion will lead to overvaluation. My results demonstrate that overvalued winners have relatively higher turnover and higher idiosyncratic volatility, both consistent with a higher divergence of opinion. 
Table 4.6

Misvaluation and Stock Characteristics (1967-2010)

This table presents time-series averages of cross-sectional average stock characteristics for portfolios used to construct the conditional momentum strategies. See Table 4.1 for additional details on the construction of these strategies. Institutional Ownership is measured quarterly as the aggregate holdings from the Thomson Reuters Institutional (13-F) Holdings database (s34) divided by shares outstanding. Turnover and Idiosyncratic Volatility are measured monthly as described in Section 3.3. Institutional Ownership is measured quarterly from 1980 to 2010, all others are based on monthly measures from 1967 to 2010. T-statistics reported below mean estimates are based on Newey-West standard errors.

\begin{tabular}{|c|c|c|c|}
\hline & MOM0, "Losers" & MOM9, "Winners" & $\mathrm{W}-\mathrm{L}$ \\
\hline \multicolumn{4}{|c|}{ Panel A: RFV (Monthly) } \\
\hline \multirow[t]{2}{*}{$\overline{\mathrm{RFV} 1, \text { Overvalued }}$} & 0.386 & 0.984 & 0.598 \\
\hline & 22.91 & 33.15 & 16.88 \\
\hline \multirow[t]{2}{*}{ RFV3, Undervalued } & -0.843 & -0.305 & 0.538 \\
\hline & -40.33 & -21.25 & 23.18 \\
\hline \multirow[t]{2}{*}{$\mathrm{U}-\mathrm{O}$} & -1.230 & -1.289 & -0.059 \\
\hline & -45.58 & -40.22 & -2.670 \\
\hline \multicolumn{4}{|c|}{ Panel B: Institutional Ownership (Quarterly) } \\
\hline \multirow[t]{2}{*}{$\overline{R F V 1, ~ O v e r v a l u e d ~}$} & 0.431 & 0.442 & 0.012 \\
\hline & 12.14 & 13.13 & 1.24 \\
\hline \multirow[t]{2}{*}{ RFV3, Undervalued } & 0.407 & 0.365 & -0.042 \\
\hline & 10.76 & 11.36 & -3.75 \\
\hline \multirow[t]{2}{*}{$\mathrm{U}-\mathrm{O}$} & -0.024 & -0.078 & -0.054 \\
\hline & -3.37 & -10.54 & -5.048 \\
\hline \multicolumn{4}{|c|}{ Panel C: Turnover (Monthly) } \\
\hline \multirow[t]{2}{*}{ RFV1, Overvalued } & 0.137 & 0.186 & 0.049 \\
\hline & 10.05 & 10.81 & 6.02 \\
\hline \multirow[t]{2}{*}{ RFV3, Undervalued } & 0.101 & 0.115 & 0.014 \\
\hline & 9.70 & 11.94 & 2.24 \\
\hline \multirow[t]{2}{*}{$\mathrm{U}-\mathrm{O}$} & -0.036 & -0.071 & -0.035 \\
\hline & -6.18 & -8.27 & -5.489 \\
\hline \multicolumn{4}{|c|}{ Panel D: Idiosyncratic Volatility (Monthly) } \\
\hline \multirow[t]{2}{*}{$\overline{\mathrm{RFV}}$, Overvalued } & 0.026 & 0.025 & -0.001 \\
\hline & 32.04 & 33.17 & -1.47 \\
\hline \multirow[t]{2}{*}{ RFV3, Undervalued } & 0.028 & 0.025 & -0.003 \\
\hline & 32.89 & 32.29 & -4.54 \\
\hline \multirow[t]{2}{*}{$\mathrm{U}-\mathrm{O}$} & 0.001 & -0.001 & -0.002 \\
\hline & 4.57 & -3.64 & -7.768 \\
\hline
\end{tabular}


While I find relatively higher divergence of opinion in overvalued winners, the institutional ownership results suggest that short-sale constraints are not binding. BDS point out that divergence of opinion and short sale constraints are jointly required for overvaluation in the Miller (1977) model. I argue that the apparent overvaluation is a result of a divergence of opinion between momentum traders and arbitrageurs, with momentum trades endogenously acting as a short-sale constraint for the arbitrageur. Overall, these results are consistent with the hypothesized interaction of arbitrageurs and momentum traders. 


\section{MOMENTUM, MISPRICING, AND THE VALUE STRATEGY}

Motivated by significantly different loadings on $H M L$ in time series tests, I explore the negative correlation between the momentum and value strategies documented in Asness (1997). Asness (1997) finds that momentum and value strategies are positively related to future returns, but are negatively related to each other. He finds that value strategies work best in past loser stocks and are least profitable in stocks classified as past winners. It seems reasonable that this negative correlation is the result of constraints on arbitrage activity imposed by momentum traders. When arbitrageurs or relative value traders expect that momentum trades will be profitable, they may reduce their capital intensity allowing mispricing to persist or deepen. ${ }^{1}$ All else equal, a reduction in arbitrage intensity allows mispricing to persist (or deepen) and results in lower returns to relative value strategies such as $H M L$. As past returns are observable, arbitrageurs may reduce the capital allocated to arbitrage opportunities in which momentum traders are trading in the opposite direction. Thus I expect the negative correlation to be the strongest in the arbitrage-impeding strategy.

To examine the influence of momentum traders on relative value traders, I compute conditional mean returns to the value strategy $(H M L)$ where the state is determined by the prior period NMOM strategy returns. As a baseline, Table 5.1, Panel A shows that $42.4 \%$ of the monthly returns to $H M L$ are less than zero while $39.8 \%$ of the monthly returns to the arbitrage-impeding strategy are unprofitable.

Table 5.1, Panel B, reports the conditional mean momentum strategy returns for each of two states defined by the lagged returns to $H M L$. The arbitrage-impeding strategy has an average monthly return of $0.34 \%$ when the prior month return to $H M L$ is profitable, and $1.36 \%$ when $H M L$ is unprofitable in the prior month. The difference in conditional means between the two states is significant ( $p$-value $=0.002)$.

${ }^{1}$ Shleifer and Vishny (1997) suggests that arbitrageurs may face funding constraints following periods of poor past performance (low returns and/or high volatility). 


\section{Table 5.1}

\section{Conditional Momentum Strategies and the Value Strategy (1967-2010)}

This table presents average momentum (value) strategy returns conditional on prior period value (momentum) strategy returns for the period 1967 to 2010. Panel A reports the percentage of months where the monthly return is less than zero for the indicated strategy. $H M L$ is the value strategy factor downloaded from Ken French's website. Construction of the (conditional) momentum strategies is detailed in Table 4.1. Panel B reports the average one-month return to momentum strategies conditioned on performance of the value strategy in the prior period. $L 1 . H M L \geq 0(L 1 . H M L<0)$ represents the average momentum strategy return when the prior period $H M L$ return is greater than or equal to (less than) zero. Panel C reports the average one-month return to the value strategy conditioned on the prior period performance of the indicated momentum strategy. $L 1 . * M O M \geq 0$ $(L 1 . * M O M<0)$ represents the average value strategy return when the prior period $* M O M$ strategy return is greater than or equal to (less than) zero. $* M O M$ represents the (conditional) momentum strategy used for conditioning the value strategy returns which is indicated in the row labeled "Conditioning Variable:." T-statistics reported below coefficient estimates are based on Newey-West standard errors.

Panel A: Percentage of strategy returns less than zero

\begin{tabular}{lcccccc}
\hline Variable: & $H M L$ & MOM & XMOM & AMOM & NMOM & NMA \\
\hline \% - Negative & 42.4 & 33.7 & 33.0 & 30.9 & 39.8 & 58.3 \\
\hline
\end{tabular}

Panel B: Average momentum strategy returns conditioned on lagged $H M L$ returns

\begin{tabular}{lccccc}
\hline $\begin{array}{l}\text { Dependent Variable: } \\
\text { Conditioning Variable: }\end{array}$ & LIOM & XMOM & AMOM & NMOM & NMA \\
\hline L1.HML $\geq 0$ & 0.85 & 1.19 & 1.46 & 0.34 & -1.12 \\
& 3.08 & 3.32 & 5.23 & 1.05 & -4.38 \\
& & & & & \\
L1.HML $<0$ & 1.50 & 1.99 & 1.78 & 1.36 & -0.42 \\
& 5.80 & 6.31 & 6.69 & 4.02 & -1.33 \\
$\begin{array}{l}\text { Test of Equality: } \\
\text { p-value }\end{array}$ & 0.0076 & 0.1379 & 0.4778 & 0.0017 & 0.0000 \\
\hline
\end{tabular}

Panel C: Average value strategy returns conditioned on lagged momentum returns

\begin{tabular}{lccccc}
\hline Dependent Variable: & $H M L$ & $H M L$ & $H M L$ & $H M L$ & $H M L$ \\
Conditioning Variable: & $L 1 . M O M$ & L1.XMOM & L1.AMOM & L1.NMOM & L1.NMA \\
\hline$L 1 . * M O M \geq 0$ & 0.15 & 0.28 & 0.45 & 0.04 & -0.16 \\
& 0.83 & 1.52 & 2.39 & 0.23 & -0.77 \\
& & & & & \\
L1.* MOM $<0$ & 0.89 & 0.64 & 0.28 & 0.94 & 0.80 \\
& 3.76 & 3.12 & 1.41 & 4.04 & 4.90 \\
Test of Equality: & & & & & \\
p-value & 0.0822 & 0.0954 & 0.3935 & 0.0283 & 0.0760 \\
\hline \hline
\end{tabular}


For the arbitrage-reinforcing strategy, there is no significant difference $(p$-value $=0.48)$ in conditional means between the two states (lagged $H M L$ profitable or not). This conditional performance of the $N M O M$ strategy (conditioned on the performance of $H M L)$ is consistent with the predicted interactions of momentum traders and arbitrageurs. When value traders are successful in keeping mispricing in check, momentum trades that rely on pushing prices away from fundamental value are relatively less successful.

Table 5.1, Panel C reports the conditional mean $H M L$ returns for each of two states defined by the lagged returns to the conditional momentum strategies. The difference in mean returns between the two states is highly significant when $H M L$ returns are conditioned on lagged $N M O M$ strategy returns and insignificant when conditioned on lagged $A M O M$ strategy returns. The mean return to $H M L$ is $0.04 \%$ when the prior period return to NMOM strategy is profitable and $0.94 \%$ when the NMOM strategy is unprofitable. However, the mean return to $H M L$ is $0.45 \%$ when the prior period returns to $A M O M$ strategy is profitable and $0.28 \%$ when it is unprofitable. The difference in means between the two states is highly significant ( $p$ value $=0.03)$ when returns are conditioned on lagged returns to the $N M O M$ strategy and insignificant when conditioned on lagged returns to the $A M O M$ strategy ( $p$ value $=0.39$ ). This conditional performance of the $H M L$ strategy (conditioned on the performance of the arbitrage-impeding momentum strategy) is consistent with the predicted interactions of momentum traders and arbitrageurs. When momentum traders are successful at pushing prices away from fundamental value, value traders are less likely to invest in apparent mispricing, allowing the mispricing to persist or deepen. Similarly, value traders profit by correcting the mispricing when momentum strategies are less profitable and possibly face funding constraints.

In a recent working paper, Asness, Moskowitz, and Pedersen (2009) show that momentum is negatively correlated with the value strategy and demonstrate that a combination of the two strategies performs better than either strategy alone. The 
source of this improved performance is unclear in light of my findings that $M O M$ and $N M O M$ each demonstrate a negative correlation with $H M L$, while $A M O M$, the strategy with the highest average returns, is positively correlated with $H M L$. The results in Table 5.1 suggest that a possible explanation of their finding is that NMOM may serve as a hedge against momentum trader risk for value-based strategies.

Together these results suggest that the arbitrage-impeding strategy and $H M L$ interact in a manner consistent with the hypothesized interaction of momentum traders and arbitrageurs. The profitability of a relative value strategy is negatively related to the profitability of the momentum strategy. When the momentum strategy is profitable, momentum traders are able to raise capital which impedes the profitability of the value traders positions. Likewise, when momentum is unprofitable, relative value traders are able to generate significant profits. 


\section{CONCLUSIONS}

Motivated by the interaction of momentum traders and arbitrageurs, this dissertation examines behavioral and rational explanations of momentum strategy profitability. I provide evidence that suggests that momentum trading is a source of risk to arbitrageurs similar to noise trader risk (De Long, Shleifer, Summers, and Waldmann (1990) and Shleifer and Summers (1990)) and as such, standard arbitrage processes may not eliminate mispricing when momentum traders and arbitrageurs trade in opposite directions.

Empirical tests show that a momentum strategy that reinforces the arbitrage process: has relatively higher returns that are largely explained as risk compensation, does not exhibit long-term reversal, and has observable differences in future growth rates between past winners and losers consistent with cross-sectional differences in ex-

pected returns. Returns to a momentum strategy that impedes the arbitrage process exhibit significant long-term reversal consistent with the model's prediction that this strategy contains relatively more mispricing (e.g. Jegadeesh and Titman (2001)) . Further, the past winners and losers in the arbitrage-impeding strategy have firm measures that are also consistent with cross-sectional differences in expected growth rates, but future corrections in price-earnings multiples suggest an overreaction to these relatively noisy signals.

Momentum trades appear to impede arbitrage when they are in opposite directions of arbitrage trades, and reinforce the arbitrage process when they are in the same direction. When momentum investors trade unconditionally with respect to fundamental value, demand pressure on overvalued winners and undervalued losers may push prices further from intrinsic value and mispricing may not be arbitraged away. It seems reasonable that rational arbitrageurs may condition the capital allocated to arbitrage opportunities on the observed past returns resulting in delayed arbitrage when momentum trades are in the opposite direction of arbitrage trades. 
Similarly, arbitrageurs may expedite arbitrage if they expect momentum trades to reinforce the arbitrage process.

Together, it appears that the profitability of the momentum strategy is largely driven by cross-sectional differences in expected returns. The mispricing component of momentum returns appears to mask the underlying cross-sectional differences in expected returns between winners and losers leading to the mixed results documented in the literature. Long-term reversal, generally associated with investor overreaction, appears to be isolated in the least profitable conditional momentum strategy and thus it is unlikely that behavioral explanations are the primary explanation of the momentum strategy's profitability. Similarly, the significantly larger proportion of momentum profits explained as risk compensation in the arbitragereinforcing strategy, which has significantly higher returns, suggests that average momentum profitability is not explained by investor underreaction.

The findings in this paper suggest that the interaction of arbitrageurs and unconditional momentum traders has implications for market efficiency. Unconditional momentum traders appear to impede arbitrage for relatively overvalued past winners and undervalued past losers. Trading strategies that do not condition on relative valuation may impose constraints on arbitrage activity in a manner consistent with noise trader risk. 


\section{REFERENCES}

Abreu, Dilip and Markus K. Brunnermeier, 2002, Synchronization risk and delayed arbitrage, Journal of Financial Economics 66, 341-360.

Amihud, Yakov, 2002, Illiquidity and stock returns: Cross-section and time-series effects, Journal of Financial Markets 5, 31-56.

Ang, Andrew, Robert J. Hodrick, Yuhang Xing, and Xiaoyan Zhang, 2006, The cross-section of volatility and expected returns, Journal of Finance 61, 259299.

Asness, Clifford S., 1997, The interaction of value and momentum strategies, $F i$ nancial Analysts Journal 53, 29-36.

Asness, Clifford S., Tobias J. Moskowitz, and Lasse H. Pedersen, 2009, Value and momentum everywhere, Working Paper.

Asparouhova, Elena, Hendrik Bessembinder, and Ivalina Kalcheva, 2010, Liquidity biases in asset pricing tests, Journal of Financial Economics 96, 215-237.

Atkins, Allen B. and Edward A. Dyl, 1997, Market structure and reported trading volume: NASDAQ versus the NYSE, Journal of Financial Research 20, 291304.

Avramov, Doron, and Tarun Chordia, 2006, Asset pricing models and financial market anomalies, Review of Financial Studies 19, 1001-1040.

Bandarchuk, Pavel and Jens Hilscher, 2012, Sources of momentum profits: Evidence on the irrelevance of characteristics, Review of Finance 0, 1-37.

Banz, Rolf W., 1981, The relationship between return and market value of common stocks, Journal of Financial Economics 9, 3-18. 
Barberis, Nicholas, Andrei Shleifer, and Robert Vishny, 1998, A model of investor sentiment, Journal of Financial Economics 49, 307-343.

Basu, S., 1977, Investment performance of common stocks in relation to their priceearnings ratios: A test of the efficient market hypothesis, Journal of Finance $32,663-682$.

Berkman, Henk, Valentin Dimitrov, Prem C. Jain, Paul D. Koch, Sheri Tice, 2009, Sell on the news: Differences of opinion, short-sales constraints, and returns around earnings announcements, Journal of Financial Economics 92, 376-399.

Boehme, Rodney D., Bartley R. Danielsen, and Sorin M. Sorescu, 2006, Short-sale constraints, differences of opinion, and overvaluation, Journal of Financial and Quantitative Analysis 41, 455-487.

Brennan, Michael J., Tarun Chordia and Avanidhar Subrahmanyam, 1998, Alternative factor specifications, security characteristics, and the cross-section of expected stock returns, Journal of Financial Economics 49, 345-373.

Chen, Nai-Fu, Richard Roll, and Stephen A. Ross, 1986, Economic forces and the stock market, Journal of Business 59, 383-403.

Chordia, Tarun and Lakshmanan Shivakumar, 2002, Momentum, business cycle, and time-varying expected returns, Journal of Finance 57, 985-1019.

Conrad, Jennifer and Gautam Kaul, 1998, An anatomy of trading strategies, Review of Financial Studies 11, 489-519.

Cooper, Michael J., Huseyin Gulen, and Michael J. Schill, 2008, Asset growth and the cross-section of stock returns, Journal of Finance 63, 1609-1651.

Cooper, Michael J., Roberto C. Gutierrez Jr., and Allaudeen Hameed, 2004, Market states and momentum, Journal of Finance 59, 1345-1365. 
Daniel, Kent, David Hirshleifer and Avanidhar Subrahmanyam, 1998, Investor psychology and security market under- and overreactions Journal of Finance 53, 1839-1885.

Daniel, Kent, and Sheridan Titman, 2006, Market reactions to tangible and intangible information, Journal of Finance 61, 1605-1643.

De Bondt, Werner F. M. and Richard Thaler, 1985, Does the stock market overreact?, Journal of Finance 40, 793-805.

De Long, J. Bradford, Andrei Shleifer, Lawrence H. Summers, Robert J. Waldmann, 1990, Noise trader risk in financial markets, Journal of Political Economy 98, 703-738.

Fama, Eugene F., 1965, The behavior of stock-market prices, Journal of Business $38,34-105$.

Fama, Eugene F., 1998, Market efficiency, long-term returns, and behavioral finance, Journal of Financial Economics 49, 283-306.

Fama, Eugene F. and Kenneth R. French, 1992, The cross-section of expected stock returns, Journal of Finance 47, 427-465.

Fama, Eugene F. and Kenneth R. French, 1993, Common risk factors in the returns on stocks and bonds, Journal of Financial Economics 33, 3-56.

Fama, Eugene F. and Kenneth R. French, 1996, Multifactor explanations of asset pricing anomalies, Journal of Finance 51, 55-84.

Fama, Eugene F. and Kenneth R. French, 2008, Dissecting anomalies, Journal of Finance 63, 1653-1678.

Fama, Eugene F. and James D. MacBeth, 1973, Risk, return, and equilibrium: Empirical tests, Journal of Political Economy 81, 607-636. 
Griffin, John M., Xiuqing Ji, and J. Spencer Martin, 2003, Momentum investing and business cycle risk: Evidence from pole to pole, Journal of Finance 58, 2515-2547.

Grundy, Bruce D. and J. Spencer Martin, 2001, Understanding the nature of the risks and the source of the rewards to momentum investing, Review of Financial Studies 14, 29-78.

Gutierrez, Roberto C. Jr. and Eric K. Kelley, 2008, The long-lasting momentum in weekly returns, Journal of Finance 63, 415-447.

Hong, Harrison, and Jeremy C. Stein, 1999, A Unified Theory of Underreaction, Momentum Trading, and Overreaction in Asset Markets, Journal of Finance $54,2143-2184$.

Jegadeesh Narasimhan, 1990, Evidence of predictable behavior of security returns, Journal of Finance 45, 881-898.

Jegadeesh, Narasimhan and Sheridan Titman, 1993, Returns to buying winners and selling losers: Implications for stock market efficiency, Journal of Finance 48, $65-91$.

Jegadeesh, Narasimhan and Sheridan Titman, 2001, Profitability of momentum strategies: An evaluation of alternative explanations, Journal of Finance 56, 699-720.

Johnson, Timothy C., 2002, Rational momentum effects, Journal of Finance 57, 585-608.

Johnson, Shane A., Theodore C. Moorman, and Sorin Sorescu, 2009, A reexamination of corporate governance and equity prices, Review of Financial Studies 22, 4753-4786. 
Kondor, Peter, 2009, Risk in dynamic arbitrage: The price effects of convergence trading, Journal of Finance 64, 631-655.

Lakonishok, Josef, Andrei Shleifer, and Robert W. Vishny, 1994, Contrarian investment, extrapolation, and risk, Journal of Finance 49, 1541-1578.

Lehmann, Bruce N., 1990, Fads, martingales, and market efficiency, Quarterly Journal of Economics 105, 1-28.

Lewellen, Jonathan, 2002, Momentum and autocorrelation in stock returns, Review of Financial Studies 15, 533-563.

Lewellen, Jonathan, Stefan Nagel, and Jay Shanken, 2010, A skeptical appraisal of asset pricing tests, Journal of Financial Economics 96, 175-194.

Liu, Laura Xiaolei and Lu Zhang, 2008, Momentum profits, factor pricing, and macroeconomic risk, Review of Financial Studies 21, 2417-2448.

Miller, Edward M., 1977, Risk, uncertainty, and divergence of opinion, Journal of Finance 32, 1151-1168.

Moskowitz, Tobias J. and Mark Grinblatt, 1999, Do industries explain momentum?, Journal of Finance 54, 1249-1290.

Novy-Marx, Robert, 2011, Is momentum really momentum?, Journal of Financial Economics (forthcoming).

Rhodes-Kropf, Matthew, David T. Robinson, and S. Viswanathan, 2005, Valuation waves and merger activity: The empirical evidence, Journal of Financial Economics 77, 561-603.

Rouwenhorst, K. Geert, 1998, International momentum strategies, Journal of Finance 53, 267-284. 
Sagi, Jacob S. and Mark S. Seasholes, 2007, Firm-specific attributes and the crosssection of momentum, Journal of Financial Economics 84, 389-434.

Shanken, Jay, 1992, On the estimation of beta-pricing models, Review of Financial Studies 5, 1-33.

Shleifer, Andrei and Robert W. Vishny, 1997, The limits of arbitrage, Journal of Finance 2, 35-55.

Shleifer, Andrei and Lawrence H. Summers, 1990, The noise trader approach to finance, Journal of Economic Perspectives 4, 19-33.

Sloan, Richard G., 1996, Do stock prices fully reflect information in accruals and cash flows about future earnings?, Accounting Review 71, 289-315. 
APPENDIX A

\section{A MODEL OF MOMENTUM TRADING AND ARBITRAGE}

The objective of this simple model is to demonstrate that under certain conditions unconditional momentum trading can impede arbitrage by affecting the arbitrageur's capital allocation decision. The intuition is straightforward; momentum trades aligned with arbitrage trades facilitate price convergence to fundamental value, while momentum trades in the opposite direction of arbitrageur trades slow price convergence and may push prices further away from fundamental value. Arbitrageurs respond by reducing arbitrage intensity when they expect momentum trades to impede price convergence, and increasing arbitrage intensity when they expect momentum trades to reinforce the arbitrage process.

Consider the case of a risk-neutral representative arbitrageur and a pair of (otherwise identical) mispriced stocks. The two stocks have identical cash flows and fundamental values, but one stock is overvalued and one is undervalued. To trade on this mispricing, the arbitrageur invests in a long-short portfolio by taking a long position in the undervalued stock and a short position in the overvalued stock. Because the arbitrageur trades offsetting long and short positions, systematic risk is eliminated from the portfolio. As the mispricing is symmetric, I will focus my discussion on one side of the transaction.

The mispriced stock can be either overvalued or undervalued and follows a price process, $p(t)=F V \pm m(t)$ where $F V$ equals the fundamental value of the stock that is observed by the arbitrageur and $m(\cdot)$ represents the level of mispricing. There is also a representative momentum trader and a representative long-term investor, neither of which possess the skill or technology required to observe the mispricing. Momentum trading is assumed to be based only on past returns (i.e. unconditional with respect to fundamental value or expected arbitrage intensity). 
This model does not consider the processes by which mispricing initially arises, but simply that a demand shock results in the initial mispricing. Mispricing is assumed to correct at some random time in the future when an exogenous event (such as widespread release of value relevant information) shifts the demand schedule of the long-term investor. ${ }^{1}$ The mispricing is such that a finite position will eliminate the mispricing. The long-term investor provides a static demand schedule, $D(\cdot)$, for the total mispricing, $m(t)$, such that:

$$
m(t)=D(z(t))=|p(t)-F V|
$$

where $z(t)$ represents time $t$ aggregate demand from arbitrage capital and follows:

$$
z(t)=x(t)+y(t) * D I R[A R B] * D I R[M O M]
$$

where $z(t)$ is net arbitrage demand for the mispriced stock, $x(t)$ is the absolute value of the arbitrageur demand in shares at time $t$ (i.e. positive for both long and short positions), $y(t)$ is the absolute value of momentum trader demand at time $t$, and $D I R[\cdot]$ is a direction function that is equal to one when the indicated trader takes a long position and negative one when the indicated trader takes a short position.

The demand schedule is denominated in terms of mispricing to simplify discussion. The demand schedule is continuous and mispricing is monotonically decreasing in $z(t)$. The momentum trader will take a long position in recent winners and short position in recent losers, while the arbitrageur will purchase undervalued stocks and sell overvalued stocks. The arbitrageur does not observe $y(t)$, but infers the direction and magnitude of $y(t)$ based on observed past returns. Together, $\operatorname{DIR}[\mathrm{ARB}]^{*} \mathrm{DIR}[\mathrm{MOM}]$ equals one when momentum trades are in the same direction as arbitrage trades (e.g. undervalued winners or overvalued losers) and negative one

\footnotetext{
${ }^{1}$ The framework of this simplified model builds on the model of risky arbitrage in Kondor (2009). In his model, an arbitrageur trades a single, fundamentally riskless security listed on two different markets where a decrease in aggregate arbitrage activity leads to a deepening in mispricing.
} 
when they are in the opposite direction (e.g. overvalued winners or undervalued losers).

To profit from the mispricing, the arbitrageur buys (sells) $x(t)$ shares of the mispriced stock when it is undervalued (overvalued). The mispricing persists over the random interval $[0, \tilde{t}]$ at which time the mispricing is eliminated by an exogenous event (i.e. $p(\tilde{t})=F V$ ). Time $\tilde{t}$ is distributed exponentially with constant hazard rate, $\delta$, and density $e^{-\delta t}$. Thus, the $\operatorname{Prob}[\tilde{t} \leq t]$ is $1-e^{-\delta t}$. The arbitrageur starts with initial capital $=c(0)$ and cannot raise additional capital for this arbitrage opportunity. The arbitrageur is required to maintain a non-negative capital position at all times $(c(t) \geq 0$ for all $t)$. For simplicity, I assume that transaction costs are zero and margin requirements are the same for both long and short positions. Given these assumptions, the arbitrageur chooses his trading position to solve the following problem:

$$
\begin{gathered}
J(c(0))=\max _{x(t)} \int_{0}^{\infty} \delta e^{-\delta t}(m(t) x(t)+c(t)) d t \\
\text { s.t. } \quad c(t)=c(0)-\int_{m(0)}^{m(t)} x(u) d m(u) \\
c(t) \geq 0
\end{gathered}
$$

The capital constraint suggests that arbitrage is risky. When time $t=\tilde{t}$ the arbitrageur profits from the correction of the mispricing $(m(t) x(t))$ and realizes the cumulative unrealized gains and losses on the position which are included in the current capital position $(c(t))$. However, if mispricing deepens to the point that cumulative losses exceed initial capital at any time $t<\tilde{t}$, the arbitrageur will be forced to close his position prior to realizing this profit. The arbitrageur's capital position is directly affected by the level of trading activity as can be seen by the marginal change in arbitrageur capital:

$$
\frac{d c(t)}{d t}=-x(t) \frac{d m(t)}{d t}=-x(t) \frac{d D(z(t))}{d z} \frac{d z(t)}{d t}
$$


Since $D(\cdot)$ is monotonically decreasing in $z(t)$, an increase in $z(t)$ results in an increase in arbitrage capital and a decrease in mispricing. Momentum trading directly effects net arbitrage capital and mispricing since $z(t)$ is increasing in $y(t) * D I R[A R B] *$ $D I R[M O M]$ :

$$
\frac{d z(t)}{d y}=\left\{\begin{array}{l}
>0 \text { when } D I R[A R B] * D I R[M O M]=1 \\
<0 \text { when } D I R[A R B] * D I R[M O M]=-1
\end{array}\right.
$$

This relation suggests that when momentum trades are in the same direction as arbitrageur trades $(D I R[A R B] * D I R[M O M]=1)$, momentum trades reduce mispricing as net arbitrageur capital increases. Similarly, when momentum trades are in the opposite direction of arbitrageur trades $(D I R[A R B] * D I R[M O M]=-1)$, momentum trades increase mispricing as net arbitrageur capital decreases.

To provide a discussion around the basic implications of this model I consider three cases: 1) no demand from momentum traders, 2) momentum trades are in the same direction as arbitrageur trades, and 3) momentum trades are in the opposite direction of arbitrageur trades. For discussion purposes, I assume that arbitrage traders trade first at each time $t$ unless otherwise noted.

Case 1 (No Momentum Traders): When there is no momentum trading activity, there is no risk in the arbitrage opportunity. To keep the model simple, momentum trades are the only source of demand shocks that can cause mispricing to deepen to a point that capital constraints are binding and the arbitrageur is forced to close his position at a loss. The arbitrageur will invest the lesser of total capital and the capital required to eliminate mispricing (e.g. $m(t)=0$ ) at time 0 and will hold the position until mispricing is eliminated by the time $\tilde{t}$ exogenous event. If the arbitrageur exits his positions prior to the event, the static demand schedule results in exiting the positions at initial cost.

Case 2 (Arbitrage-Reinforcing Momentum Traders): In this case, momentum traders take a long position in undervalued past winners or a short position in over- 
valued past losers. The demand pressure from momentum trades pushes prices towards fundamental value (i.e. static demand schedule). All else equal, mispricing will be lower and there is no risk that mispricing will deepen. If there was another source of risk in the model, such as noise trader risk or fundamental risk, momentum trades would lower the total risk of an arbitrageur being forced to close his position prior to correction of mispricing at $\tilde{t}$. Since the arbitrageur trades first, he will maximize his profit by investing the lesser of total capital and the capital required to eliminate mispricing (e.g. $m(t)=0$ ) at time 0 . If the momentum trader trades first, the arbitrageur would trade the lesser of $F(0)-y(t)$ shares and total capital where $F(\cdot)$ is the inverse demand schedule with $F(m(t))=z(t)$. All else equal, demand pressure from momentum traders may shift the stock's price such that the arbitrageur can exit his position with a gain (dependent upon the level of momentum trader demand) prior to time $\tilde{t}$.

Case 3 (Arbitrage-Impeding Momentum Traders): In this case, momentum traders take a long position in overvalued past winners or a short position in undervalued past losers. All else equal, demand pressure from momentum trades pushes prices away from fundamental value. Demand pressure from momentum trades $(y(t))$ may move the stock's price such that the arbitrageur faces a loss when exiting his position prior to time $\tilde{t}$. If $x(t)-y(t) \geq 0$, the static demand schedule suggests that momentum traders reduce the effect of arbitrage capital and mispricing persists. If $x(t)-y(t)<0$, the static demand schedule suggests that mispricing will deepen. This demand pressure from momentum traders increases the risk that the arbitrageur is forced to close his position prior to correction of mispricing at $\tilde{t}$. As the arbitrageur trades first and $y(t)$ is unobservable, the arbitrageur must infer the level of $y(t)$ from the observed past returns. Because of the risk that mispricing will deepen, the arbitrageur's allocation to the arbitrage opportunity $(x(t))$ will be strictly less than his 
available capital $(c(t))$ when observed past returns suggest that momentum traders will trade in the opposite direction of arbitrageurs. ${ }^{2}$

This model suggests that demand from momentum traders can affect the allocation of arbitrage capital and as a result has a significant impact on market efficiency. Their trades may reinforce the arbitrage process causing mispricing to correct faster, or they may impede the arbitrage process enabling mispricing to persist and in some cases deepen. The model suggests that an arbitrage-impeding momentum strategy contains more mispricing than an arbitrage-reinforcing strategy. ${ }^{3}$ This result follows from the reduction in net arbitrage capital (net arbitrage capital = arbitrage capital plus effect of momentum capital) which results in persistence of mispricing, all else equal. Thus arbitrage-reinforcing momentum capital speeds price convergence (increases net arbitrage capital) while arbitrage-impeding momentum capital impedes price convergence (reduces net arbitrage capital). ${ }^{4}$

When unconditional momentum trades are in the opposite direction of arbitrageur trades, the demand from momentum traders can slow price convergence and may push prices further away from fundamental value. From the arbitrageur's perspective, unconditional momentum trading can cause mispricing to deepen and thus represents a risk similar to noise trader risk (e.g. DeLong, Shleifer, Summers, and Waldmann (1990) and Shleifer and Summers (1990)). Like noise trader risk, arbitrageurs may not be able to directly observe momentum trading activity. However, arbitrageurs

${ }^{2}$ The arbitrageur's capital allocation choice is consistent with the model of Kondor (2009) where a strictly positive probability of a loss results in an optimal capital allocation which may not completely eliminate the mispricing in a given arbitrage opportunity. This is also consistent with the impact of noise trader risk on arbitrage activity (e.g. De Long, Shleifer, Summers, and Waldmann (1990) and Shleifer and Summers (1990)).

${ }^{3}$ Demand pressure from arbitrage-reinforcing momentum trades pushes prices towards predicted fundamental value regardless of whether apparent misvaluation is due to "true" mispricing or omitted risk factors. Arbitrage traders do not directly observe mispricing and may also trade apparently misvalued securities pushing them towards peer or industry-average valuations. All else equal, the combined trading activity should reduce the actual level of mispricing.

${ }^{4}$ Abreu and Brunnermeier (2002) develop a model of synchronization risk where holding costs compel competitive arbitrageurs to strategically time their trades based on their expectations of other arbitrageur trading activity resulting in delayed arbitrage. In a similar manner, arbitrageurs may time the market by conditioning their trades on the expectations of the level and direction of momentum trading activity where expectations are based on observed past returns. 
can infer the direction and intensity of momentum trading by observing past returns. Thus, it seems reasonable that past returns can lead to a reduction in arbitrage intensity if arbitrageurs condition their level of investment on past returns. 


\section{VITA}

\section{William Joseph Armstrong}

Department of Finance

Cell: $\quad 979.220 .1588$

Texas A\&M University

Fax: 979.845 .3884

360 Wehner Building, 4218 TAMU

E-Mail: warmstrong@mays.tamu.edu

College Station, TX 77843-4218, USA

E-Mail: willjarmstrong@hotmail.com

- Education

○ University of Colorado, Boulder: B.S.

- Texas A\&M University: M.B.A.; Ph.D.

- Awards and Honors

- Dean's Award for Outstanding Teaching by a Doctoral Student, 2010-2011

- Best Paper in International Finance Award, On Stock Returns and the Exchange Rate Puzzle (with Johan Knif, James W. Kolari and Seppo Pynnönen), Midwest Finance Association, 2010

- Invited Academic Seminars

- Texas Tech University, 2011; Mississippi State University, 2011 